\title{
Short-Term Options: Clienteles, Market Segmentation, and Event Trading
}

\begin{abstract}
We compare clientele and information share in weekly- (Weeklys) and monthly-expiring options (Monthlys) on the S\&P 500 index. Striking dissimilarities between the two instruments are found, most apparent being the much smaller trade size and substantially higher implied volatility in Weeklys, consistent with both speculation and event trading. Additionally, the price discovery contribution of Weeklys, albeit modest when compared to the underlying index itself, is substantially larger than that of Monthlys. The cumulative evidence points to an increasingly segmented options market. Thus, studies employing only standard options to investigate price discovery will likely underestimate the informational role of options.

Key words:
\end{abstract}

Weeklys, Monthlys, Greeks, Implied Volatility, Spread, Price Discovery

JEL: G130 


\section{Introduction}

This study addresses two important questions about clienteles and information share in short-term options (STOs). First, do STOs cater to a different clientele vis-a-vis standard options? This question, relating to potentially different investor clienteles, follows naturally from the stated objectives of exchanges in listing STOs. The Chicago Board of Options Exchange (CBOE) introduced weekly-expiring options (Weeklys) on the S\&P 500 Index primarily to fulfill the needs of short-term traders $122^{3}$ Along these lines, we know from prior work that clienteles form at certain venues because of trading motivations and preferences in trade sizes (see e.g., Bauer, Cosemans, and Eichholtz (2009), Barclay and Warner (1993), Chakravarty (2001), and Alexander and Peterson (2007), among others). In a second question, we ask if STOs play a larger role than standard options in price discovery? There are good reasons to believe that Weeklys play a significant informational role. Several authors advance leverage inherent in options as important to this role (see Black (1975), Easley, O'Hara, and Srinivas (1998), Kaul, Nimalendran, and Zhang (2002), Pan and Poteshman (2006), and Chakravarty, Gulen, and Mayhew (2004)). In theory, traders should find it preferable to participate in the cheapest, most leveraged venue for trading, as long as there is sufficient liquidity. Based on these qualifications, it would seem that Weeklys should attract clienteles who seek these advantages. Another reason to suspect that STO trades

\footnotetext{
${ }^{1}$ Their nomenclature reflects "weekly" expirations. When Weeklys were first introduced they had a shelf life of just one week, but beginning June 2012, Weeklys have had longer shelf lives (out to almost 5 weeks). Throughout their tenure though, pre- and post-June 2012, Weeklys have always been set up in such a manner that there is always a series that expires during any given week, other than the week Monthly options expire. Hence, the terminology "Weeklys" have always reflected their expirations and not their shelf lives.

${ }^{2}$ Weeklys on the S\&P 500 are the most seasoned of exchange traded STOs, first traded under a Securities and Exchange Commission pilot program in 2005, and becoming a regular offering at the CBOE in early 2010. Subsequently, several exchanges introduced other Weeklys, and by mid-2010, they were also traded on individual stocks and ETFs.

${ }^{3}$ Certain option strategies become more attractive with Weeklys. For example, covered call writing, when employing Weeklys, would limit the time exposure of option writers. A more subtle advantage offered by Weeklys is that it is P.M. settled on expiration-Friday. Therefore, traders can manage their positions until expiration itself. Monthly expiring options typically expire on a Saturday, with trading ceasing on Thursday at 4:00 p.m. and settlement based on Friday's opening index value, leaving writers exposed to overnight moves in the Index.
} 
may be non-trivial is the possibility that Weeklys traders may be relatively more focused on proximate events. Yan and Zhang (2009) evaluate the performance of short-term versus long-term equity traders and offer divergent views about possible outcomes: (i) a trader who can regularly identify undervalued/overvalued assets will likely trade more frequently to exploit this informational advantage. Therefore, the transactions of a short-horizon trader may contain more information about proximate events, however, (ii) active/short-term trading could simply be symptomatic of noise trading. If the former is indeed true, Weeklys could be a source of contribution to price discovery.

The notion that Weeklys could contribute to price discovery has underpinnings in the literature - informational trading in the Treasuries and option index markets. Brandt and Kavajecz (2004) show that changes in the yield curve in Treasury markets is related to the aggregation of heterogeneous private information. Along these lines, Green (2004) finds a significant increase in the informational role of Treasury trading following macroeconomic announcements. Chatrath et al. (2009) also detect the presence of informed trading in Treasury markets and note that Treasury dealers face information asymmetries, but in a less conventional sense $\mathrm{H}^{4}$ Evidence of private information has also been detected in index options (see Kang, Ahn, and Ryu (2008)). Kang et al. (2008) examine options on the KOSPI 200 index. These options are among the more actively traded derivatives. They document significant information asymmetry and attribute this finding to informed trading of public information. More to the point, Becker, Clements, and McClelland (2009) also find that the VIX index not only subsumes information relating to past jump contributions to total volatility, but also reflects incremental information pertaining to future jump activity. This background suggests the possibility that trading in Weeklys could reflect important information. While firm-specific information can be a source of informational trading in index options (for example, pending an announcement of a new product or a legal settlement

\footnotetext{
${ }^{4}$ They note that the bid or ask quote that a dealer submits to inter-dealer brokers is held firm for two minutes unless it is transacted upon, or a new and more favorable post occurs. The firmness of the quotes leaves the dealer vulnerable for a period of time during which market conditions may change.
} 
that is expected to move markets), trading in the Weeklys is also likely to reflect market-wide events.

The two questions we ask, about clienteles and price discovery, posed together, allow us to address yet another important question: has the introduction of STOs resulted in segmented options markets? Such considerations are of large import to regulators, exchanges, and market participants. With these considerations in mind, we employ for comparative purposes with Weeklys, standard monthly-expiring options on the S\&P 500 Index (Monthlys).

\subsection{Lines of Inquiry}

Below, we provide details about the specific lines of inquiry pursued in this study.

\section{A. Clientele Effects}

To evaluate potential differences in clienteles between Weeklys and Monthlys, we examine several parameters including trade size, implied volatility, spreads and depths, among others.

Trade size, as we noted earlier, is an important indicator about the identity of market participants. The comparison of implied volatility between the two options allow for assessment of whether there is a special premium reflected in Weeklys prices, possibly arising from their popularity among event or target traders. Detection of such a premium will also explain the preference of STOs among option writers. On the other hand, evidence of similar implied volatilities between Weeklys and Monthlys point to a competitive marketplace in which Weeklys offer more flexibility, without imposing any additional premia.

We track option spreads and depths (the trade size backing the bid and ask prices) across contract expiration cycles; this is to gauge how dealers view trading in both markets. Chakravarty, Gulen, and Mayhew (2004) note a positive link between price discovery and bidask spreads, consistent with the argument that writers impose an adverse selection premium for informed trading. Uncovering evidence of vastly different spread and depth components between Weeklys and Monthlys will indicate that dealers view clienteles in the two markets differently. Along these lines, we also estimate violations in call option bounds between the two contracts to determine if there is systematic mispricing of option cross-sections (see e.g., 
Constantinides et al. (2009)). Lastly, we examine how well the two markets are integrated by following the work of Kapadia and $\mathrm{Pu}(2012)$.

\section{B. Information Effects}

We examine information share in the two contracts employing Hasbrouck's (1995) information share measure (IS) $!^{5}$ Chakravarty, Gulen, and Mayhew (2004) find the IS of options markets to be around 17\%. Dong and Sinha (2011) document an even larger IS for index options. In our approaches, we assess IS across each day of Weeklys trading, and for robustness checks, we examine Weeklys trading around macro-events (i.e., "Save-the-Euro" events). If Weeklys draw event traders, then such trades should be more discernible on those days.

In concluding the introduction, we briefly preview our main findings.

We find

(a) clienteles between the two markets to be strongly distinguishable on several criteria. Weeklys experience smaller trade sizes, and trade with much narrower relative spreads than Monthlys. The larger relative spreads in Monthlys reflect inventory and order-processing considerations. Weeklys also carry substantial volatility premiums, vis-a-vis Monthlys. There is also evidence of call option boundary violations in Weeklys but not in Monthlys. However, an examination of a more recent sample show these violations to largely disappear. Tests also show the two markets to be still not fully integrated.

(b) informed trading to be present in both markets, but that price discovery and information share is larger in Weeklys than in Monthlys.

In summary, the evidence points to segmentation between the two markets and that they cater to different clienteles. Such an outcome is likely in line with the intentions of exchanges that offer these instruments. Moreover, our findings have a bearing on academic studies examining informational discovery; such studies may miss crucial information if they ignore STOs.

\footnotetext{
${ }^{5}$ The IS is similar to the component-share measure proposed by Harris, McInish, and Wood (2002) in that it focuses on establishing the proportion of price discovery that occurs in a particular market.
} 
The remainder of the paper is organized as follows. In the next section we describe the data and sampling methods. Section 3 presents the empirical findings and proposes an explanation that reconciles the overpayment-informed trading phenomenon. Section 4 concludes and summarizes our findings.

\section{Data and Sampling Methods}

The data employed in a majority of tests span the interval January 2011 through May 2012. By the beginning of 2011, Weeklys were firmly established as a trading vehicle at the CBOE; moreover, the interval employed is one of relative financial calm, with the S\&P 500 volatility normalizing to around $20 \%{ }^{6}$ More importantly, Weeklys are exclusively 7 -day options during this period.

Our data consists of Trade and Level I quote data for the S\&P 500 Weeklys and Monthlys and is from the CBOE's Option Price Reporting Authority (OPRA) 7 Over the same interval, intraday data on the S\&P 500 Index are also employed. The index values are available every 15 seconds of the trading day in 2011, and every 5 seconds in 2012. We focus on both tradeand quote-side market activities. The data provide several variables of interest, including: the date and time (to the nearest millisecond) of the trade/quote, the trade/quote indicator, the OPRA sequence number, trade price, bid price, bid size, ask price, ask size, class symbol (i.e., SPXW (Weeklys) and SPX (Monthlys)), put/call indicator, expiration date, strike price, and days to expiration. We sample the data, starting at the open of trading at 9:30 a.m. Eastern Standard Time, until the close of trading at 4:00 p.m.

Several standard filters are applied to the data. First, trades with price less than $\$ 0.15$ are eliminated from the sample. Second, quotes with bid price less than $\$ 0.15$ or bid (ask)

\footnotetext{
${ }^{6}$ There is precedence that return distributions implied by options prices is closer to lognormal over periods of market stability. On the other hand, periods immediately following large disruptions obtain distributions that are systematically skewed to the left (e.g., Jackwerth and Rubenstein (1996)). Comparing statistics obtained from two options with minor differences in moneyness could thus be more problematic in stressful market conditions.

${ }^{7}$ The authority gathers quotes and transaction data from both electronic and physical exchanges. See Birru and Figlewski (2012) for more on OPRA data.
} 
size equal to zero are removed. Third, options whose prices violate the lower boundary conditions are also removed. Moreover, these are European style options, and thus, our statistics are not impacted by issues relating to early exercise.

By design, Weeklys are not written for the week when Monthlys expire. This presents an empirical challenge in some instances, because Weeklys and Monthlys with the same time to expiration are not available for a simple side-by-side comparison. We address this problem in straightforward ways. First, we compare Weeklys and Monthlys by lining up the two contracts by days to expiration and moneyness. Specifically, the data are restricted to ten days or less to expiration. This allows us to compare both the behavior of traders, as well as option features such as volatility and Greeks, while imposing controls for expiration. Our focus on the final days of Monthlys also circumvent the problem associated with model selection 8 The advantage of such controls become even more apparent when we discuss relationships between time to expiration, moneyness, and our variables of interest. This approach, though, relies on observations that are obtained from different weeks of the calendar. To ensure that our findings are simply not an artifact of such sampling, we conduct a second, real time (or calendar time) analysis that compares Weeklys and Monthlys at a given point in time, but with different maturities. With real time tests, expiration effects cannot be explicitly controlled for. In instances where both sampling techniques need robustness checks, we subject the analysis to additional tests with a sample from June 2012 to December 2012. Beginning June 2012, Weeklys traded with longer expirations (up to 5 weeks) ${ }^{9}$

As a precursor to the analysis that follows, and as an affirmation of the growing popularity and liquidity of Weeklys, in Figures 1-3, we compare daily volume and trade-frequency patterns between Weeklys and Monthlys over the period January 2011 to December 2012.

\footnotetext{
${ }^{8}$ It has been shown that both Black-Scholes and stochastic-volatility options models obtain different volatility estimates, and that these differences are sensitive to time to expiration (e.g., Bakshi, Cao, and Chen (2000)).

${ }^{9}$ We employ the trade price in almost all of our tests except in IS estimations, where we use quotes. The use of quotes in these estimations can be problematic (see Ioffe and Prisman (2013)). Because of this we also address the IS issue by employing alternate short-horizon lead-lag regressions.
} 
The number of trades, in addition to volume, are also shown in order to provide more evidence about the liquidity of Weeklys 10

From Figures 1 and 2, for volume and number of trades, respectively, it is evident that the growth in Weeklys trading is not accompanied by a similar growth in Monthlys, suggesting that growth in the former might have come at the expense of the latter. This could also indicate a movement of short-term traders to Weeklys and away from Monthlys, given the convenience Weeklys offer. The plots in Figure 3, presented for Weeklys as a percentage of Monthlys, provides a sharper view of the rising popularity of STOs. In January 2011, the total volume of Weeklys (puts and calls) hovered around 15\% of total Monthlys volume (puts and calls). But, by the end of 2012, this figure is much greater, rising to around $42 \%$. In fact quite frequently (on 63 days), Weeklys volumes are in excess of more than half of Monthlys volumes. The corresponding beginning and ending values for Weeklys trades as a percentage of Monthlys are $70 \%$ and 126\%, respectively. Additionally, on 350 days, Weekly trades are more than half of Monthly trades, and on 186 days, Weeklys trades actually exceed Monthly trades. The purported healthy liquidity of Weeklys is borne out by the data itself.

\section{Insert Figures 1 to 3 about here.}

\section{Empirical Results}

The empirical results are presented in the following manner. First, we provide introductory statistics - volume patterns across Weeklys and Monthlys. Next, we undertake tests that help draw inferences about trader identity/clienteles in Weeklys and Monthlys. A third set of tests relate to price discovery and Information Share (IS). Finally, we conduct empirical experiments to reconcile seemingly contradictory evidence in Weeklys between pricing premia and price discovery.

\footnotetext{
${ }^{10}$ Ane and Geman (2000) suggest that number of trades is important to prices (also, see Jones, Kaul, and Lipson (1994)).
} 


\subsection{Volume Patterns}

Table 1 reports statistics for near-the-money (NTM) options for Weeklys and Monthlys, respectively. ${ }^{11}$ The statistics are reported by proximity to the final seven days of trading: $6, \ldots, 0$, where day 6 is the initiation day (Thursday) for Weeklys and day 0 is the final trade day (Friday). Because Monthlys typically expire on a Saturday, with trading ceasing on the preceding Thursday at 4:00 p.m. and settlement based on Friday's opening index value, day 0 for this contract is typically the third Thursday of each month.

\section{A. Weeklys}

We provide two key statistics, volume and share of total volume, and several patterns emerge. First, volume is larger in puts than in calls. Given that the put/call ratio for well-established stock index option markets are typically much higher than 1 , this result is not unexpected. Second, we find in Table 1 Weeklys volume changes across the expiration week; there is a dramatic rise in call volume as expiration approaches. For instance, the call volume on day 6 is only $8.13 \%$ of total call volume, but rises to $15.49 \%$ on day 3 , and then to $16.85 \%$ on day 0 . The penultimate trade day for calls (day 1) attracts the largest volume $(19.56 \%)$. For puts, the pattern shows similarities. Volume on day 6 is around $8.8 \%$ of total put volume, but rises to $13.01 \%$ on day 3 , and to $15.61 \%$ on day 0 . The penultimate trade day for puts (day 1) also attracts the largest volume (21.29\%).

\section{B. Monthlys}

Interestingly, the statistics for Monthlys in Table 1 shows NTM put volume, relative to Weeklys, to be even more substantial than calls. Put Weeklys volume is about $12 \%$ more than corresponding calls, whereas with Monthlys it is almost double this value (around $24 \%$

\footnotetext{
${ }^{11}$ We employ the moneyness definition in Jiang and Tian (2005) where, for call options, moneyness is defined as $m_{t}=K / S_{t}$, where $K$ is the strike price, and $S_{t}$ is the current (index) price level. Using this definition, we categorize options into five moneyness categories: deep in-the-money (DITM) with $m \leq 0.9$, in-the-money (ITM) with $0.9<m \leq 0.97$, near-the-money (NTM) with $0.97<m \leq 1.03$, out-of-the-money (OTM) with $1.03<m \leq 1.1$, and deep out-of-the-money (DOTM) with $m>1.1$. For a put option, the moneyness definition is the inverse of a call option's definition. The bulk of trading (volume) is in NTM options (around $65 \%$ of the total). Statistics for options other than NTMs are available from the authors on request. However, these statistics add little insight beyond what is offered by NTM options.
} 
more). Differences in patterns in puts and calls are also noted for Monthlys as the final trade date approaches. The share of volume in Monthly calls is at $11.11 \%$ on day 6 , and grows to $19.96 \%$ on the final trade date, while the share of put volume on day 6 is $10.99 \%$ but rises to $23.68 \%$ on the final trading day. Unlike Weeklys, the highest volumes traded for Monthlys is on day 0. Also, Weeklys call and put volume tends to coalesce toward each other around expiration, whereas Monthlys call and put volumes tend to diverge from each other.

On a related note, Monthlys volume in all moneyness categories over trade days 0-6 represent about $25 \%$ of the combined volume for trade days 7-38 ${ }^{12}$ As expected, the further away from expiration, the more diffuse is volume across moneyness categories. Nonetheless, even away from expiration, NTM Monthlys remain the most liquid.

\section{Insert Table 1 about here}

\subsection{Trader Identity}

In these tests, we continue to primarily focus on the final seven days of trading, but for robustness, we also provide summary results from real time sampling. The most important comparison between the two contracts centers around trade size and implied volatility.

\section{A. Trade Size}

Panel A of Table 2 reports trade size over each of the final seven days of trading for NTM contracts and also for two configurations, samples (0-6, 0-6) and (2-6, 0-4). When we examine samples (0-6, 0-6), we look at Weeklys through their expiration day (typically, Thursday, Friday,..., Friday), but for Monthlys, only to their last trading day (typically, Wednesday, Thursday,..., Thursday). Because of this, tests of differences between Weeklys and Monthlys are also conducted over other configurations: (1-6, 0-5) and (2-6, 0-4). The comparative test results are very similar in their implications. For brevity, we report only results that correspond to $(0-6,0-6)$ and $(2-6,0-4)$. Note that the $(2-6,0-4)$ configuration moves the expiration-date proximity in favor of Monthlys, i.e., Monthlys are now sampled

\footnotetext{
${ }^{12}$ We ignore Monthlys volume in excess of 38 days in this study as it is of little relevance for our purposes.
} 
closer to their expirations than Weeklys. The alternate sequencing, (0-6, 0-6) and (2-6, 0-4), establishes stability in our test results, and more importantly, allows assessment of whether expiration day effects play any overriding role in our findings.

From the evidence in Table 2, it becomes clear that there are substantial differences in trade size between the two markets. For calls, the average trade size for Monthlys is between 3 and 4 times larger than that of Weeklys. For instance, on day 1, Weeklys calls average 14.265 contracts, whereas Monthlys calls are more than three times this size (52.70). For puts, this difference is even more pronounced, with Monthlys trade size between 3 and 6 times larger than Weeklys. On day 2, for instance, Weekly puts average 15.274 contracts, whereas corresponding Monthlys average 64.44. These differences are substantial whether one compares trade size across each day, or over samples based on proximity to final trading day ${ }^{13}$ For results showing percentiles, we find that NTM trade size by percentiles differ over days (0-6) between Weeklys and Monthlys across the entire spectrum of transactions. For put Weeklys, the smallest trades ( $25^{\text {th }}$ percentile) average 1 contract, and the largest trades $\left(95^{\text {th }}\right.$ percentile) average 50 contracts, and the vast majority ( $75^{\text {th }}$ percentile) of trading in Weeklys is for 10 contracts. Correspondingly, for Monthly puts, the smallest and largest trades are 2 and 300 contracts, respectively, and the majority average around 42 contracts. Based on trade size patterns, it appears that Weeklys and Monthlys cater to different clienteles. It is possible that such differences in trade size for the largest trades may have to do with the depth of the market, wherein market-makers are unwilling to transact on extreme-sized trades in Weeklys. But, this explanation has little merit because large differences in trade size between Weeklys and Monthlys are present across the entire spectrum of transactions.

Trade sizes, compared in real time, are shown in Panel B of Table 2, wherein Weeklys trading in days 0-6 are conducted against trading in the nearest-to-expire Monthlys. Large difference in trade sizes continue to hold even when sampling in this manner. Monthly puts

\footnotetext{
${ }^{13}$ For instance, the average trade size for calls on Weeklys and Monthlys over the seven final trading days, (0-6, 0-6), are 13.71 and 50.45, respectively; a similar magnitude of difference is also noted when we compare the means from days (2-6, 0-4), 14.23 and 48.87 , respectively.
} 
and calls average close to 5 and 4 times Weeklys puts and calls, respectively.

We also examine clienteles in the two markets by examining changes in option Greeks. These results are not reported in the interest of brevity ${ }^{14}$ The evidence from these tests show that such changes, in almost all instances, are significantly larger in Weeklys than in Monthlys; when this is not the case their differences are insignificant. For instance, Weeklys changes in deltas, gammas, and thetas are on average (in absolute terms) $200 \%$ larger than corresponding changes in Monthlys, confirming that the two contracts exhibit differentiable price behavior and likely draw differing clienteles.

\section{Insert Table 2 about here}

\section{B. Model Free Implied Volatility (MFIV)}

To examine implied volatility in the two contracts, we use the MFIV approach formalized by Britten-Jones and Neuberger (2000). They define the model-free implied variance as:

$$
E_{0}^{F}\left[\int_{0}^{T}\left(\frac{d F_{t}}{F_{t}}\right)^{2}\right]=2 \int_{0}^{\infty} \frac{C^{F}(T, K)-\max \left(0, F_{0}-K\right)}{K^{2}} d K
$$

where $E^{F}$ refers to expectation under the forward probability measure, $C^{F}(T, K)$ is the forward price of a call option with maturity $T$ and strike $K$, and $F_{0}$ is the forward price of the underlying asset at time $t$. We assume that the underlying asset does not pay a dividend, the risk-free rate is zero, and returns follow a diffusion process. Jiang and Tian (2005) propose a practical approach on how to extract the model-free risk-neutral higher moments. The MFIV has two dimensions, (a) time to expiration and (b) strike prices. For a given time $T$, the MFIV can be extracted, if there exists a set of strike prices of calls when the time to maturity equals $T$. Since time to maturity of options vary, it is not possible to always have a fixed set of option with maturity $T$ on any dates. In the literature, most studies use a fixed $T=30$ days. To extract the 30 day MFIV, interpolation techniques are

\footnotetext{
${ }^{14}$ These results are available from the authors on request.
} 
used. In practice, the VIX index is a simplified version of the MFIV 15

With this procedure, to extract the MFIV, we use one set of options with maturities less than 30 days to expiration (Weeklys) and another set with more than 30 days to expiration (Monthlys). At any point in time, there are at most two sets across the trading week of expirations (on Thursdays and Fridays) or one set of expirations (Mondays, Tuesdays, and Wednesdays). Thus, it is not possible to construct a fixed (T) MFIV calculation for Weeklys. To be able to still compare the volatility prices of Weeklys and Monthlys in meaningful ways, we take, what we consider to be, a reasonable approach by estimating the MFIV for the nearest Monthly and the nearest Weekly (note that for days with two sets of Weeklys, we use the closest to expiration set). Thus, $T$ varies from day to day and $T$ is different for Weeklys and Monthlys. This is the best we can do, given the data limitations. Other than this, we follow the same approach as in Jiang and Tian (2005). We estimate MFIV for every minute in the sample and compare the distributions of the two time series. Table $3 \mathrm{a}$ Panel A reports MFIV measures for NTM options for the two contracts to their last day of trading and Panel B reports corresponding measures for real-time sampling, in the configurations $(0-6,0-6)$ and $(2-6,0-4)$.

Across each trading day, the MFIV is systematically distinguishable between Weeklys and Monthlys. The largest difference is noted on the last day of trading ( 0.341 for Weeklys versus 0.154 for Monthlys). Another interesting feature is the systematic increase in MFIV for Weeklys from day $6(0.220)$ to day $0(0.341)$, a feature that is not present in Monthlys. In fact, a decrease in MFIV is noted for Monthlys with corresponding values of 0.210 (day 6) and 0.154 (day 0). Comparing mean values over configuration (0-6) (0-6), Weeklys implied

\footnotetext{
${ }^{15}$ The VIX calculation measures 30-day expected volatility of the S\&P 500 Index. The components of the VIX calculation are near- and next-term put and call options with more than 23 days and less than 37 days to expiration. These include SPX options with "standard" $3^{r d}$ Friday expiration dates and "weekly" SPX options that expire every Friday, except the 3rd Friday of each month. Once each week, the SPX options used to calculate VIX "roll" into new contract maturities. For example, on the second Tuesday in October, the VIX index would be calculated using SPX options expiring 24 days later (i.e., "nearterm") and 31 days later (i.e., "next-term"). For more see the VIX White Paper by CBOE. The link is: http://www.cboe.com/micro/vix/vixwhite.pdf
} 
volatility is 0.243 whereas Monthlys is around 0.194, with Weeklys exhibiting premiums of about 25\%. Even with the other configuration, (0-4) (2-6), Weeklys exhibit a premium of around $22 \%$ (0.231 versus 0.189$)$. Simply put, implied volatility premiums are detected in Weeklys even when we exclude expiration- and pre-expiration days from the sample. The second set of columns report MFIV by percentile. These figures show MFIV to be even more disparate when volatility is extremely elevated between Weeklys and Monthlys. Consider the configuration $(0-6,0-6)$. The $95^{\text {th }}$ percentile is 0.479 for Weeklys, but only 0.338 for Monthlys, a premium of about $41 \%$. Weeklys MFIV is also relatively large at the lowest $\left(25^{\text {th }}\right)$ percentile: 0.164 versus 0.139 for Monthlys. Similar findings, although the contrasts are not as sharp, are noted with real-time sampling.

In Figure 4, we plot the MFIV distributions which show the daily average MFIV measure for Weeklys and Monthlys. The graph underpins the evidence in Table 3a, indicating that the MFIV for Weeklys is almost always larger than the MFIV of Monthlys across the sample period. Taken together, the evidence noted here, consistent with the evidence on trade size and Greeks, show the two markets appearing to cater to two different clienteles. ${ }^{16}$

To examine the source of the larger implied volatility premium being paid for Weeklys we later examine a potential culprit - target or event trading. It is highly plausible that option writers recognize the urgent needs of target traders in Weeklys (who are typically small), and thus, assess a premium. ${ }^{17}$ From the perspective of options buyers, it appears that traders (those targeting specific days) search out the lowest priced options in absolute terms; these will more often be Weeklys, and a premium is paid on these options, making them more expensive in relative terms ${ }^{18}$

\section{Insert Table $\mathbf{3 a}$ about here}

\footnotetext{
${ }^{16}$ Detail about MFIV higher moments are provided in Appendix A.

${ }^{17}$ Liquidity differences do not appear to be a reasonable explanation for large volatility premiums in Weeklys. First, liquidity, as defined by number of trades, is fairly comparable between Weeklys and Monthlys. Second, it is arguable that lower liquidity should favor lower, not higher, prices.

${ }^{18}$ We also examine differences in the Black-Scholes implied volatility measure for NTM options for both contracts. The evidence from these tests is highly consistent with the results from the MFIV measure.
} 


\section{Insert Figure 4 about here}

\section{Price of Volatility Risk}

A related and useful statistic to extract is the (negative) price of volatility risk. We compute this statistic for each instrument as the MFIV-RVOL, where RVOL is the realized forward-looking volatility (the standard deviation of the $n$-day return). The daily return is calculated on an overlapped $\mathrm{S} \& \mathrm{P} 500$ index for every minute and the P-distribution is measured using the corresponding $n$-day forward looking daily return. For example, the one-day return at 9:40 on day $d$ is the logarithmic difference between the index value at 9:40 on day $d$ and the index value at 9:40 on day $d-1$.

In general, given the evidence in the literature, a finding of a negative premium in the two contracts, in itself, will not be surprising. Several studies uncover negative premiums in index options data (see e.g., Bakshi and Kapadia (2003), Bondarenko (2004), and Carr and Wu (2009)). For example, Bakshi and Kapadia (2003) examine if the volatility risk premium is negative by examining the statistical properties of delta-hedged portfolios and find that their results strongly support a negative premium. Our results are reported in Table 3b below.

We find the negative price of volatility risk to be much larger for Weeklys than for Monthlys. For example, on day 0 this value is 0.180 for Weeklys, almost five times larger than the corresponding value for Monthlys (0.037). Another striking pattern is that the disparity between Weeklys and Monthlys increase as we get closer toward the last day of trading. Notice that compared to day 0 , on day 6 the values are smaller and closer to each other, 0.068 and 0.058 for Weeklys and Monthlys, respectively. Such striking differences, especially so close to expiration, between Weeklys and Monthlys are again suggestive of differing clienteles ${ }^{19}$

\footnotetext{
${ }^{19}$ From a theoretical perspective, our results are consistent with the stylized fact that the implied volatility of an option exceeds the physical volatility of the underlying asset. Based on Heston's (1993) model and a pricing kernel assumption, Christoffersen et al. (2013) suggest that an equity risk premium $(\mu)$ and a
} 
In the next section we see how dealers/market-makers perceive Weeklys traders relative to Monthlys traders, by examining spreads, depths, and potential call option boundary violations.

\section{Insert Table $3 \mathrm{~b}$ about here}

\section{Spreads and Depths}

Table 4 provides statistics, in configurations similar to trade size, on the relative bid-ask spread (RS) and depth for NTM options. Note that the RS for each intraday observation is given by the difference in the quoted bid- and ask price, standardized by the average of these prices. The depth is the sum of the bid size and ask size. The bid-ask spread is commonly understood to be a positive function of illiquidity and information asymmetry (see e.g., Copeland and Galai (1983), Amihud and Mendelson (1986), and Glosten and Milgrom (1985), among others). Several studies also show an inverse relationship between depth and asymmetric information, and by association, an inverse relationship between depth and spread (see e.g., Lee, Mucklow, and Ready (1993), Brennan and Subrahmanyam (1995)).

The results in Table 4 show a substantially higher RS for Monthlys in each of the seven days as well as in the two configurations $(0-6,0-6)$ and $(2-6,0-4)$. For example, the average RS for calls over days $0-6$ is $17.8 \%$ for Monthlys, but only $8 \%$ for Weeklys. For puts, the corresponding figures are $17.3 \%$ and $7.8 \%$. The scale of RS is not surprising in itself, as the close-to-expiration NTM options trade with very large spreads on account of their heightened Gammas. However, the magnitude of their differences is surprising. Monthlys RS is almost

$\overline{\text { variance risk premium }(\lambda) \text { can be expressed }}$ as a function of preference (averse) parameters as follows:

$$
\begin{aligned}
\mu & =-\phi-\xi \sigma \rho \\
\lambda & =-\rho \sigma \phi-\sigma^{2} \xi=\rho \sigma \mu-\left(1-\rho^{2}\right) \sigma^{2} \xi
\end{aligned}
$$

Here, $\rho$ is the correlation coefficient between the stock market returns and variance, $\sigma$ is the variance of variance, $\phi$ is the risk-aversion parameter, and $\xi$ is the variance preference parameter. Both empirically and theoretically, $\mu$ has been shown to be positive, and empirically, the correlation between stock market returns and variance $\rho$ is found to be strongly negative. Following the arguments in Christoffersen et al. (2013), both $\phi$ and $\xi$ are positive. Thus, $\lambda$ has to be negative; our results are consistent with these arguments. 
twice that of Weeklys RS. ${ }^{20}$

The next set of columns in Table 4 are for depth. Following volume and size statistics, the depth figures are expectedly in favor of Monthlys. However, these differences do not appear to be substantial. The average depth for calls (puts) over days 0-6 is 169 (170) for Weeklys versus 188 (188) for Monthlys. They are even smaller when we exclude the final days of trading (see $(2-6,0-4))$. The fact that depth falls off sharply in the final day of trading for both options is consistent with the notion that risks are elevated for NTM options, especially with only a few hours to expiration. Overall, the differences in depth between Monthlys and Weeklys are not found to be substantial ${ }^{21}$ Thus, it appears that although there are disparities between the two market trade sizes, the depths backing these sizes are not as disparate.

In Panel B of Table 4, a summary of spread and depth figures obtained via real time sampling of Weeklys and Monthlys is shown. The difference between RS in this comparison is narrower than in Panel A of Table 4, only $3 \%$ and $4 \%$ for calls and puts, respectively. The smaller RS for Monthlys in Panel B, compared to Panel A, is to be expected because spreads typically decline with time-to-expiration. With regards to depth, we find differences between Weeklys and Monthlys to be much higher in Panel B than in Panel A. Again, this too is expected because risk-averse market makers offer greater depth for NTM options farther away from maturity, when inventory-management errors are likely to be less costly.

\footnotetext{
${ }^{20}$ In results that we do not report for brevity, we find similar patterns when we examine the effective spread $\left(E S_{t}\right)$, which provides an assessment of the expense borne for a round-trip transaction. The effective spread is computed as $E S_{t}=P_{t}-\frac{1}{2}\left(P_{t}^{B}+P_{t}^{A}\right)$, where $P_{t}$ is the transaction price, and $P^{B}$ and $P^{A}$ are bid and ask prices. The average effective spread for Weekly calls (puts) over days 0-6 is $15 \%$ (18\%), and for Monthlys is $41 \%$ (57\%). The narrower Weeklys effective spreads imply that they are cheaper to trade. However, the advantage of Weeklys from narrower spreads is countered by their larger implied volatility. For instance, with an average price of a NTM option with 5 days to expiration being about $\$ 10$ over our sample, the effective spread differences on this day, approximately -0.30 , comprises only a few percentage points in potential savings.

${ }^{21}$ We separately compute Kyle's Lambda (Kyle (1985)), an alternate proxy for depth, by regressing the absolute percent change in the price of an option on its trading volume over a particular period. The regression coefficients are statistically indistinguishable (at the 1 percent level of significance) between Monthlys and Weeklys for each of the final seven trade dates.
} 


\section{Insert Table 4 about here}

The evidence presented for the spreads lead to an interesting question: why is the relative spread in Weeklys smaller than that found in Monthlys? One possible explanation is that trade size is smaller in Weeklys, so that the dealers' inventory-holding risks are much more manageable in this market. If this is indeed the case, inventory and order processing costs should be an important factor that explains these differences. Another complementary explanation is that dealers perceive the Weeklys market to be less informed, so they do not impose a premium for adverse selection. We examine this explanation in additional tests that assess these alternative explanations via a systematic comparison of adverse selection and inventory/order processing components of the spread. The findings from these tests, not reported in the interest of brevity, suggest that differences in spreads between the two markets better reflect inventory/order processing considerations. If at all, the evidence with adverse selection, albeit weak, suggests that more informed trading occurs in Weeklys than in Monthlys, particularly with put options.22

\section{E. Violations of Call Option Bounds}

To examine boundary violations in Weeklys we follow the methodology in Constantinides, Jackwerth, and Perrakis (2009), and also draw from Constantinides, Czerwonko, Jackwerth, and Perrakis (2011). Following their approaches, we identify a stochastic violation when the bid (ask) price implied volatility is higher (lower) than the upper (lower) bound ${ }^{23}$ We briefly describe the procedure we follow.

At any time prior to expiration, the following is a partition-independent upper bound on the price of a call:

$$
\bar{c}\left(S_{t}-t\right)=\frac{1+k}{(1-k) R_{S}^{T-t}} E\left[\left[S_{T}-K\right]^{+} \mid S_{t}\right],
$$

where $R_{S}$ is one plus the expected return on the stock (or in our case the Index) per period

\footnotetext{
${ }^{22}$ These results are available from the authors on request.

${ }^{23}$ Note that these violations appear in both studies but are explicitly mentioned and hold center stage in Constantinides et al. (2011).
} 
and $k$ is the transaction cost, which we assume is set to zero. The other notation follows standard nomenclature. The assumption of zero transaction cost is harmless and makes comparisons between Weeklys and Monthlys easier. Moreover, the zero cost assumption provides tight boundaries. The lower bound is then given by:

$$
\underline{\mathrm{c}}\left(S_{t}, t\right)=(1+\delta)^{t-T} S_{t}-K / R^{T-t}+E\left[\left[K-S_{T}\right]^{+} \mid S_{t}\right] / R_{S}^{T-t},
$$

where $R$ is one plus the risk-free rate per period, which we set to zero, and $\delta$ is the dividend yield. We also assume that the dividend yield is zero. Note that setting the dividend yield to zero again is reasonable, particularly since we are dealing with 4 day to expiration Weeklys. Thus, the lower bound is then approximately:

$$
\underline{\mathrm{c}}\left(S_{t}, t\right)=S_{t}-K+E\left[\left[K-S_{T}\right]^{+} \mid S_{t}\right] / R_{S}^{T-t} .
$$

Constantinides et al. (2009) study the stochastic dominance bounds of options with 30 days to expiration. Due to the characteristics of Weeklys, we are unable to do this. Instead, for Weeklys, we examine the stochastic dominance bounds for options with 4 days to expiration. Following their approach, we estimate the unconditional distribution over the whole history of S\&P 500 index (1951- May 30, 2012). Then, for each day, we use the VIX index to rescale the volatility of the unconditional distribution. This is potentially a better approach vis-a-vis Constantinides et al. (2009). In their study, they rescale the volatility of the unconditional distribution in each panel using the average implied volatility (IV) for each subperiod. But, averaging the IV is problematic because of its variance. The IV can be dramatically different from one day to another. Our approach better lends itself to providing more precise estimates. Using the rescaled distribution of each day, we estimate boundaries. Of course, the daily boundaries themselves may not be the same.

Next, for each day in the sample, we compare the implied volatility of the bid prices of calls within the 9:30 a.m. to 11:00 a.m. interval to their upper boundaries. Similar to 
Costantinides et al. (2009), we select the most active one-minute interval (i.e., the one minute for a particular option with the most quotes). Because of this, the one-minute interval may not be the same for different options. For each of the days within the sample, we calculate the upper boundary, using the average index level in this interval, as the spot price for moneyness (strike price over current index level) for values between 0.9 to 1.1 with a step of 0.01 . Thus, our moneyness definition includes OTM to ITM options. We then use linear interpolation to calculate the upper boundary for each of the options whose moneyness is not precisely at 0.9, 0.91, etc., (most of them are not). Following this, we count the total number of options within each of the intervals $[0.9,0.91),[0.91,0.92)$, etc., and then compute the percentage of bid price violations of the stochastic dominance boundaries. We find substantive violations of the upper boundary. To illustrate these violations, we plot below, the upper and lower boundaries for 4 days to expiration Weeklys, along with the percentage of violations. ${ }^{24}$ On the other hand, in corresponding tests of lower boundaries of Weeklys, we find almost no violations.

Just like with Weeklys, for Monthlys, we calculate upper and lower boundary violations, but for 30 days to expiration calls. The results are very similar to Constantinides et al. (2009), in that we do not observe any major violations of upper or lower boundaries. Also, in additional tests, with the extended sample (June 2012 - December 2012), where Weeklys trade for extended periods, we find the call upper bound violations to largely disappear, mimicking the findings with Monthlys during the same period 25

\section{Insert Figure 5 about here.}

\section{F. Market Integration between Weeklys and Monthlys}

Given the evidence of differing clienteles between the two markets, in an additional step, we assess the level of integration between Weeklys and Monthlys. We follow Kapadia and

\footnotetext{
${ }^{24}$ Note that these findings are robust to different transaction cost assumptions and different risk-free rate assumptions.

${ }^{25}$ These results are available from the authors on request.
} 
$\mathrm{Pu}$ (2012) and use a similar statistical measure of market integration for the two contracts. Given that there are no Weeklys and Monthlys with the same time to maturity traded on the same dates, we match the expiring Weeklys with the nearest-term Monthlys for this step. In any event, this pairing should well suffice with respect to detecting the level of integration between the two markets.

Let $P_{W}$ and $P_{X}$ represent put-call parity implied index levels for 4-day maturity Weeklys and the nearest-term Monthlys, respectively. Assume that on a given date, we have $i=$ $1, \ldots, n$ observations for $P_{W}$ and $P_{X}$, and we define $\Delta P_{i, W}^{j}=P_{W}(i+j)-P_{W}(i)$, and $\Delta P_{i, X}^{j}=$ $P_{X}(i+j)-P_{X}(i)$, for $1 \leq j \leq n-1$, and $i \leq n-j$, for Weeklys and Monthlys, respectively. Then a pair of implied prices (implied from Weeklys and Monthlys) presents a possible arbitrage opportunity if $\Delta P_{i, W}^{j} \Delta P_{i, X}^{j}<0$. (This suggests that implied prices from Weeklys and Monthlys move in different directions in a given interval of time - one price goes up while the other goes down). Note, our definition is opposite to that of Kapadia and $\mathrm{Pu}$ (2012); they deal with credit spreads and stock prices.

Analogous to Kapadia and $\mathrm{Pu}$ (2012), we define market integration for Monthlys and Weeklys on the frequency of observations of such arbitrage opportunities. More specifically, we define this as

$$
\hat{\kappa}=\sum_{j=1}^{n-1} \sum_{i=1}^{n-j} 1_{\left\lfloor\Delta P_{i, W}^{j} \Delta P_{i, X}^{j}<0\right\rfloor} .
$$

This measure takes into account all pairings of $P_{W}$ and $P_{X}$ on a given date. There is a one-to-one correspondence between $\hat{\kappa}$ and the Kendall correlation (Kendall, 1938). Defining $\kappa$ as the Kendall correlation, we have

$$
\kappa=\frac{4 \hat{\kappa}}{n(n-1)}-1
$$

where $\kappa$ is a value bounded by -1 and 1 . In the absence of mispricing, $\kappa=-1$. Our results for $\kappa$ and the t-statistics of the t-test of H0: $\kappa=-1$ are shown below ${ }^{26}$

\footnotetext{
${ }^{26}$ Note that we calculate the implied prices every 15 seconds in 2011 and every 5 seconds in 2012.
} 
The $\kappa$ value has a minimum of -0.986 and a maximum of -0.672 , and averages -0.909 . When we examine how integrated the two markets are on days when macroeconomic news, such as when the Unemployment Report, is released, we do not uncover much additional insight. For example, on days the Unemployment Report is released, the $\kappa$ value ranges from -0.98 to -0.78 , and just like with the full sample averages around -0.9027 These results indicate that although the probability of arbitrage is low between the two markets, they are still not fully integrated, a finding that suggests they likely cater to different clienteles.

\begin{tabular}{llllll}
\hline \hline$H_{0}$ & Mean & Std.Dev & Max. & Min. & $\mathrm{T}$ \\
\hline$\kappa=-1$ & -0.909 & 0.0563 & -0.672 & -0.986 & 26.07 \\
\hline \hline
\end{tabular}

To better illustrate the behavior of the $\kappa$ value, we also include a time series analysis of the integration variable in the graph below. The graph shows the oscillation of $\kappa$ between its its maximum and minimum values. We find that for a little more than $95 \%$ of the time, the integration variable $\kappa$ is less than -0.75 , about $65 \%$ of the time, it is less than -0.90 , and around $24 \%$ of the time less than -0.95 .

\section{Insert Figure 6 about here}

\subsection{Information and Price Discovery}

The second part of our analysis examines the potential roles of the two contracts in price discovery. We evaluate Hasbrouck's (1995) Information Share (IS) of Weeklys, Monthlys, and the S\&P 500 Index. In a complementary test we also employ short-horizon lead-lag regressions.

\section{A. Information Share}

The Hasbrouck (1995) Information Share (IS) measure is premised on cointegrated price series and a common implicit efficient price. In the presence of arbitrage, prices on a single

\footnotetext{
${ }^{27} \mathrm{~A}$ test that the mean of $\kappa$ on Unemployment Report release days is equal to the mean $\kappa$ of the entire sample cannot be rejected. The full results from these tests are available from the authors on request.
} 
asset obtained from different trading venues will move towards a common price. The proportion of variance of this price attributable to a specific venue is its IS. But, in the case of index options, even though they may be linked to the Index via arbitrage, they may still not be cointegrated. Two approaches are used to circumvent this problem and extract an option's implied price series: (a) using a measure for volatility and extracting underlying prices using the Black-Scholes model, or (b) extracting prices using put-call parity. Chakravarty et al. (2004) follow the former, employing the standard deviation of the lagged 30-minute underlying asset return as their constant volatility measure and use it to extract implied prices from the Black-Scholes model. Muravyev et al. (2013), on the other hand, use put-call parity to construct an option implied price series.

In a recent study, Czerwonko et al. (2012) criticize the use of lagged implied volatility for its lack of precision in the presence of volatility smiles/smirks. ${ }^{28}$ They also point out that the "true" option price is unknown at any moment, and its value is generally proxied by the midpoint of the (extremely wide) option bid-ask spread. Thus, the midpoint price will include microstructure noise, as does the contemporaneously observed underlying price. Consequently, the lagged implied volatility method uses an unbiased implied volatility estimate, but its error variance is expected to be high because of the inherent error components and thus, gives noisy estimates for the implied price. Using the average of the available put-call pairs to identify implied prices smoothens this noise, but it boosts an option's IS (Czerwonko et al. (2012)). Thus, a preferred approach in addressing these issues is to employ the nearest at-the-money (ATM) put-call pairs. We use the put-call parity approach and take the nearest ATM put-call pair, and then verify the IS for both Weeklys and Monthlys. In robustness checks, we re-estimate the IS by also taking the next-to-nearest ATM pairs, and additional such pairs (2nd nearest, 3rd nearest,... to the 10 th nearest) 29

The IS methodology has now become standard practice, thus, we avoid describing the

\footnotetext{
${ }^{28}$ Ackert and Tian (2001) find few violations in put-call parity between the index options and the Index, even while noting that there are "inefficiencies" within the options market.

${ }^{29}$ The results with the other pairs are found to be qualitatively similar.
} 
procedure in the interests of brevity. Details about the method are provided in Hasbrouck (1995) and Baillie et al. (2002), among others. Table 5 reports the IS measure for the final seven days of trading. In this framework, we estimate IS in a bivariate fashion, first for S\&P 500 and Weeklys (first set of columns), and then for the S\&P 500 and Monthlys (second set of columns).

The results (high (maximum) and low (minimum) statistics) suggest that the Index is the main source of information. In the first pairing (Index-Weeklys) the Index IS ranges from $95 \%$ to $98 \%$ at the maximum, and $70 \%$ to $85 \%$ at the minimum. In comparison, Weeklys IS range from $14 \%$ to $30 \%$ at the maximum, and $2 \%$ to $5 \%$ at the minimum. The highest IS for Weeklys appear close to their initiation days - maximum and minimum IS values for Weeklys is $30 \%$ on day 5 , and $2 \%$ on day 5 , respectively. These findings indicate that the IS for Weeklys although modest is still non-trivial. On the other hand, in the second pairing, the corresponding IS for Monthlys is relatively smaller, with its maximums ranging between $2 \%$ and $6 \%$, and its minimums ranging from $1 \%$ to $2 \%$. The Index maximums range from $98 \%$ to $99 \%$, and minimums range from $94 \%$ to $98 \%$ in this pairing. Thus, it appears that Monthlys play a much smaller role than Weeklys in price discovery.

We conduct additional tests for IS in a trivariate setting. The evidence from these tests are even more convincingly in favor of Weeklys. Also noteworthy, in an examination over opening (trade) hours or closing hours, or over low-volatility and high-volatility days, the order of IS importance remains intact (first Index, followed by Weeklys, and then Monthlys). In fact, on high volatility days, we find an even greater difference in IS favoring Weeklys over Monthlys ${ }^{30}{ }^{31}$

In a complementary approach to price discovery, we employ a series of lead-lag regressions and consider relative price discovery between Weeklys and Monthlys. For this, implied prices

\footnotetext{
${ }^{30}$ These results are available from the authors on request.

${ }^{31}$ Czerwonko et al. (2012) indicate that tick size reduction by CBOE (i.e., minimum price movement) in 2007 contributed to larger IS in options. Given that Weeklys and Monthlys have the same tick sizes, we can rule out tick size as a likely contributor to differences in IS between the two contracts.
} 
are derived from put-call parity to investigate short horizon leadership vis-a-vis the S\&P 500 index ${ }^{32}$ The findings from these tests are consistent with those from the IS examination, in both magnitude and order. The $\mathrm{S} \& \mathrm{P}$ index continues to be the most important venue for determining near-horizon index returns, followed by Weeklys, and then Monthlys. In fact, Monthlys returns are not statistically important in a majority of sampling intervals, and consistently carry the smallest regression coefficient. On the other hand, Weeklys implied returns appear to be important to subsequent movement in the index almost throughout their life, with returns on days 3, 0 , and 6 being especially noteworthy in this sense.

\section{Insert Table 5 about here}

\section{B. Information Share, Macroeconomic News, Weeklys and Monthlys Expira- tions}

It is possible that the detection of higher IS in Weeklys is simply symptomatic of their (more frequent) closer time to expiration vis-a-vis Monthlys. If this is indeed the case, it may be that options traders, in general, are more sensitive to news closer to expiration. We examine the issue in the following manner. Using data after June 2012 to December 2012 (when Weeklys trade with multiple (extended) expirations), we first match the expiring Monthlys with the nearest-term Weeklys, effectively turning the tables on our mode of sampling for IS tests reported so far. Now Monthlys are closer to expiration vis-a-vis Weeklys. To illustrate, if Monthlys expire on September $22^{n d}$, we match trades in this contract with Weeklys expiring on September $29^{\text {th }}$, on the following dates: 09/17/12 (Monday) through to 09/20/12

\footnotetext{
${ }^{32}$ For these tests we use the following framework. Let $p^{W}$ and $p^{M}$ represent the implied index values from NTM Weeklys and Monthlys options, respectively, we define their returns as $R_{t}^{W}=\ln \left(p_{t}^{W}\right)-\ln \left(p_{t-1}^{W}\right)$ and $R_{t}^{M}=\ln \left(p_{t}^{M}\right)-\ln \left(p_{t-1}^{M}\right)$, where $(t-1, t)$ represents an intraday interval. We examine their respective roles in "discovering" the underlying index via the lead-lag regression:

$$
R_{t}^{S P}=\alpha_{0}+\alpha_{1} R_{t-1}^{M}+\alpha_{2} R_{t-1}^{W}+\alpha_{3} R_{t-1}^{S P}+\varepsilon_{t},
$$

where $R^{S P}$ is the corresponding intraday return on the S\&P 500 index. In this case, we look toward leadership vis-a-vis the S\&P 500 index returns, rather than to an efficient common price as in IS. We sample prices at their highest frequency, 15 seconds in 2011, and 5 seconds in 2012, and estimate regressions for seven samples, each relating to days to expiration for Weeklys. The results are available from the authors on request.
} 
(Thursday). We do this with all Monthlys expirations in the extended sample. In a second and similar match, the same Monthlys contract is compared with the furthest-term Weeklys. The latter match adds even greater separation between Monthlys and Weeklys expirations, and again is in favor of Monthlys in terms of days to expiration. Thus, if Weeklys continue to exhibit a larger IS than Monthlys under these alternate pairings, then expiration effects can clearly be ruled out as the source of Weeklys price leadership. In fact, it is reasonable to then conclude that Weeklys larger IS better reflects its clientele.

We show the results for the first pairing in Table 6 (pairing with the nearest-term Weeklys). The findings from the other pairing is strikingly similar and can be made available from the authors on request. We find the IS for Weeklys to be always larger than Monthlys. For instance, on day 3 in the Monthlys expiration cycle, the IS for Weeklys is 0.845 whereas for Monthlys the IS is only 0.155. The higher IS in Weeklys appears to be more symptomatic of its clientele.

\section{Insert Table 6 about here}

The above experiment also allows an examination of how IS is distributed when macroeconomic releases take place, but only during Monthlys expiration weeks. The news releases that tend to be released during the last seven days of Monthlys trading are the inflation indexes, the CPI and PPI. Thus, in the above experiment we examine how IS is distributed during scheduled CPI and PPI releases. Thus, the larger IS in Weeklys appears robust to even news releases during Monthlys expirations.

\subsection{Discussion: Reconciling the Evidence}

Of all the major differences we uncover between Weeklys and Monthlys, perhaps the most intriguing are patterns in trade size, implied volatility, and the measures of price discovery. First, trade size is substantially smaller in Weeklys, suggesting that relatively small traders

populate this venue. Second, implied volatility is substantially higher in Weeklys, indicating 
large premia on the price of these options. Also, implied volatility rises as one approaches Weeklys expiration. In fact, on the final days of trading, implied volatility in Weeklys is twice as large as Monthlys. Not surprisingly, we also find a rapid time-decay in Weeklys as "overpricing" corrects. Third, we find Weeklys to be more informative in the sense of IS and information leads, exhibiting price leadership over Monthlys in short-horizons. Thus, on the one hand, Weeklys appear to be the venue for small traders who seemingly "overpay" for these options, but on the other hand, they are also found to be the venue for greater price discovery. The evidence, at first blush, may seem to conflict, but a simple explanation shows that this is indeed not the case. The results suggest the presence of short-term/eventbased trading in Weeklys not found in Monthlys, as one of the more important sources of these symptoms. If event traders enter the Weeklys markets in larger numbers, vis-a-vis Monthlys, we would expect to see relatively larger volumes in Weeklys versus Monthlys, especially around important events. Additionally, to cope with the rising influx of event traders to Weeklys markets, market-makers extract a premium, and in the process, hedge themselves against potential losses, and give rise to large implied volatilities in Weeklys. More to the point, event traders with their larger volumes may also contribute to the informational advantage (greater price discovery) in Weeklys over Monthlys. Thus, a run-up in volume prior to scheduled events will underpin these explanations. We evaluate this explanation more directly by examining volume and implied volatility using data sampled just prior to a set of major events in our sample.

We employ several meetings relating to "Save the Euro" crisis over our sample, January 2011 - May 2012. The meetings are highly consequential for financial markets and involve Euro Zone leaders, either as Prime Ministers/Presidents or Finance Ministers/Central Bankers ${ }^{33}$ Appendix B lists these events and provides a brief description about their nature. Undeniably, these meetings were one of the most closely watched series of sustained

\footnotetext{
${ }^{33}$ Note that Ait-Sahalia et al. (2012) find that macroeconomic and financial sector policy announcements in several key economic zones, including the euro area, have significant effects on interbank credit and liquidity risk premia during the recent financial crisis.
} 
economic events during our sample period.

To control for expiration effects in volume and implied volatility, we first compute expiration-adjusted trading volume and implied volatility for each trading day for calls and puts. For a given trading day $t$, with $j$ days to expiration, the deviations in volume is given by:

$$
V_{t}^{A}=\left(V_{t}^{j}-\overline{V_{j}}\right) / \overline{V_{j}},
$$

where $j$ represents days to final trade date, $j=6, \cdots, 0$ for Weeklys, and $j=34, \cdots, 0$ for Monthlys. $V^{A}$ is then the abnormal component (innovation) ${ }^{34}$ Daily values for $V_{t}^{j}$ and $\overline{V^{j}}$ are obtained using the average of intraday volume. Similarly, abnormal implied volatility is constructed as:

$$
I V_{t}^{A}=\left(I V_{t}^{j}-\overline{I V_{j}}\right) / I \overline{V_{j}} .
$$

The formulations in equations (8) and (9) represent percentage-abnormal volume and implied volatility, respectively. Because the Euro Zone and EU meetings are frequently held over 2 consecutive trading days, we have dual event-days. Table 7 reports these variables by event day.

The results show strong support for greater event trading effects in Weeklys vis-a-vis Monthlys. For both Weeklys and Monthlys, volume and implied volatility are substantially elevated prior to these dates. For instance, with calls (Panel A), the abnormal trading volume in Monthlys is $21 \%$ and $14 \%$ over the two days $(-3,-2)$ preceding the event. However, the corresponding elevation in volume is even greater in Weeklys, at $44 \%$ and $24 \%$. For call implied volatility, we find similar patterns over the pre-event days. Monthlys implied volatility is elevated by $20 \%$ and $25 \%$ over days -3 and -2 , but Weeklys implied volatility is elevated by $21 \%$ and $52 \%$, respectively. The results from put options (Panel B) are strikingly similar. Notice that these patterns reverse over the event days and beyond, with Monthlys

\footnotetext{
${ }^{34}$ In order to investigate responses over all Euro Zone events, we use the full sample of trade days for Weeklys $(0,1,2, \ldots, 6)$ and use an extended sample for Monthlys $(0,1,2, \ldots, 34)$.
} 
exhibiting relative elevation in trading activity and implied volatility. Similar findings appear in another experiment we conduct using the monthly Unemployment Report as the event. Once again, we find a stronger run up in expiration-adjusted volume and implied volatility in Weeklys than in Monthlys. These results are available from the authors ${ }^{35}$ In summary, Weeklys trading activity and its pricing of calls and puts appear to be notably elevated over the run-up to the event vis-a-vis Monthlys. The observed pricing premia in Weeklys thus may be construed, at least in good part, to event-focused trading.

\section{Insert Table 7}

\section{Summary and Conclusions}

We conduct a comparative investigation of weekly- (Weeklys, SPXW) and monthlyexpiring (Monthlys, SPX) S\&P 500 index options. In principle, shorter-term options should provide greater leverage to traders. This advantage and the liquidity available in Weeklys can be used as arguments for supporting short-term trading activities. Our goals are to identify: (i) the type of clientele the two options venues attract, and (ii) the role Weeklys play, relative to Monthlys, in contributing to price discovery in the S\&P 500 index. The results from such an analysis carry implications as to whether the introduction of short-term options have led to segmented option markets.

For almost all of our tests, we employ trade and quote data for Weeklys and Monthlys over the period January 2011 through May 2012. In this period, Weeklys trade exclusively as 7day options. This enables us to draw very precise conclusions. The two options are compared using two matching techniques. First, Weeklys and Monthlys are sampled separately over their final seven trading days. This approach controls for expiration effects. Second, Weeklys and Monthlys are sampled in real time (simultaneous trading). The latter approach controls for exogenous (market-related) factors that could affect both contracts.

\footnotetext{
${ }^{35}$ Donders and Vorst (1996) also find implied volatilities of call options on firms increase significantly in an event period prior to firm news announcements, and reach a maximum on the eve of such announcements. Also, following the news releases, implied volatilities decline sharply and move back to their long-run levels.
} 
To examine clienteles we look at several dimensions: (a) trade size and option Greeks, (b) implied volatility and the price of volatility risk, (c) spreads, depths, and the adverse selection components of the spread, (d) call option boundary violations, and (e) market integration. We find Weeklys and Monthlys to be distinguishable on almost all criteria examined. Weeklys witness smaller trade sizes, trade with smaller spreads, and carry substantial implied volatility premiums as compared to Monthlys. For example, the implied volatility for NTM Weeklys is about $3 \%$ to $7 \%$ higher than corresponding Monthlys (in absolute terms). The higher relative price of Weeklys is consistent with event-induced premia, wherein traders pay a fee for event-based trading. We also find significant differences in option Greeks between the two contracts. There is evidence of call option boundary violations in Weeklys but not in Monthlys. Tests also show the two markets to be not fully integrated. In sum, the evidence points to the two markets catering primarily to two different clienteles.

Differences in information share between Weeklys and Monthlys are examined with two approaches. First, we employ Hasbrouck's Information Share (1995), in a bivariate and trivariate setting, and second, we employ a series of short-horizon lead-lag regressions. For the first approach, we employ put-call parity implied prices of Weeklys and Monthlys, along with the price of the underlying S\&P 500 index. We uncover a relatively higher information share for Weeklys. This informational advantage exists irrespective of whether the examination is in expiration or real time. Robustness tests are also conducted to address any misgivings that the relatively higher information share found in Weeklys is simply symptomatic of their (more frequent) closer time to expiration. The evidence using lead-lag regressions, reinforces the Information Share approach, providing compelling evidence that Weeklys play an important role in options price discovery.

Of all the differences that we find between Weeklys and Monthlys, the most striking are differences in trade size, implied volatility, and measures of price discovery. At first blush, these findings may seem to be at odds. Small trade size in Weeklys is suggestive of the presence of relatively small traders in this venue. Implied volatility is also substantially 
higher in Weeklys, indicating that these traders pay large premia on the price of these options. Yet, Weeklys also exhibit relatively higher information share, a finding more compatible with informed trading. In an experiment, we demonstrate that these findings are all in agreement and point, in good measure, to event trading in Weeklys contributing to the differences between Weeklys and Monthlys. It appears that the transactions of a short-horizon traders contain information about proximate events (see also Yan and Zhang (2009)).

In summary, the results show the two markets supporting different clienteles: shorthorizon traders in Weeklys, and longer-horizon traders in Monthlys. Viewed in this light, the CBOE's offering of Weeklys could be considered a success. Thus, it should not be surprising to see exchanges offering shorter-horizon options in other markets and even shorter maturities (daily or intraday). Our findings also have an important bearing for academic research examining the contributions of options to price discovery. Ignoring short-term options in such an examination may lead to underestimation of the leadership role options play. 


\section{References}

[1] Ackert, L.F., Tian, Y.S., 2001. Efficiency in index options markets and trading in stock baskets. Journal of Banking and Finance 25, 1607-1634.

[2] Aït-Sahalia, Y., Andritzky, J., Jobst, A., Nowak, S., Tamirisa, N., 2012. Market response to policy initiatives during the global financial crisis. Journal of International Economics 87, 162-177.

[3] Alexander, G., Peterson, M.A., 2007. An analysis of trade-size clustering and its relation to stealth trading. Journal of Financial Economics 84, 435-471.

[4] Amihud, Y., Mendelson, H., 1986. Asset pricing and the bid-ask spread. Journal of Financial Economics, 17, 223-249.

[5] Ane, T., Geman, H., 2000. Order flow, transaction clock, and the normality of asset returns. Journal of Finance 55, 2259-2284.

[6] Baillie, R., Booth, G., Tse, Y., Zabotina, T., 2002. Price discovery and common factor models. Journal of Financial Markets 5, 309-321.

[7] Bakshi, G., Cao, C., Chen, Z., 2000. Pricing and hedging long term options. Journal of Econometrics 94, 277-318.

[8] Bakshi, G., Kapadia, N., 2003. Delta hedged gains and the negative volatility risk premium. Review of Financial Studies 16, 527-566.

[9] Barclay, M., Warner, J., 1993. Stealth trading and volatility: Which trades move prices? Journal of Financial Economics 34, 281-305.

[10] Bauer, R., Cosemans, M., Eichholtz, P., 2009. Option trading and individual investor performance. Journal of Banking and Finance 33, 731-746.

[11] Becker, R., Clements, A.E., McClelland, A., 2009. The jump component of S\&P 500 volatility and the VIX index. Journal of Banking and Finance 33, 1033-1038.

[12] Birru, J., Figlewski, S., 2012. Anatomy of a meltdown: The risk neutral density for the S\&P 500 in the fall of 2008. Journal of Financial Markets 15, 151-180.

[13] Black, F., 1975. Fact and fantasy in the use of options. Financial Analysts Journal 31, $36-41$.

[14] Black, F., Scholes, M., 1973. The pricing of options and corporate liabilities. Journal of Political Economy 81, 637-654.

[15] Brandt, M., Kavajecz, K., 2004. Price discovery in the U.S. Treasury market: The impact of order flow and liquidity on the yield curve. Journal of Finance 59, 2623-2654.

[16] Brennan, M., Subrahmanyam, A., 1995. Investment analysis and price formation in securities markets. Journal of Financial Economics 38, 361-381. 
[17] Britten-Jones, M., Neuberger, A., 2000. Option Prices, Implied Price Problems, and Stochastic Volatility. Journal of Finance 55(2), 839-866.

[18] Bondarenko, O., 2004. Market price of variance risk and performance of hedge funds. SSRN Working Paper, 1-50.

[19] Carr, P., Wu, L., 2009. Variance risk premia. Review of Financial Studies 22 (3),13111341.

[20] Chakravarty, S., 2001. Stealth Trading: Which Traders' Trades Moves Prices? Journal of Financial Economics 61, 289-307.

[21] Chakravarty, S., Gulen, H., Mayhew, S., 2004. Informed trading in stock and option markets. Journal of Finance 49, 1235-1257.

[22] Chatrath, A., Christie-David, R.A., Lee, K., Moore, T., 2009. Competitive inventory management in treasury markets. Journal of Banking and Finance 33, 800-809.

[23] Christoffersen, P., Heston, S., Jacobs, K., 2013. Capturing Option Anomalies with a Variance Dependent Pricing Kernel. Forthcoming, Review of Financial Studies. doi: $10.1093 /$ rfs/hht033.

[24] Constantinides, G.M., Czerwonko, M., Jackwerth, J.C., Perrakis, S., 2011. Are Options on Index Futures Profitable for Risk Averse Investors? Journal of Finance 66, 1407-1437.

[25] Constantinides, G.M., Jackwerth, J.C., Perrakis, S., 2009. Mispricing of S\&P 500 index options. Review of Financial Studies 22, 1247-1277.

[26] Copeland, T., Galai, D., 1983. Information effects on the bid-ask spread. Journal of Finance 38, 1457-1469.

[27] Czerwonko, M., Khoury, N., Perrakis, S., Savor, M., 2012. Tick size, microstructure noise, informed trading and volatility inversion effects on price discovery in option markets: Theory and empirical evidence. Working paper, University of Quebec, Montreal.

[28] Donders, M.W.M., Vorst, T.C.F., 1996. The impact of firm specific news on implied volatilities. Journal of Banking and Finance 20, 1447-1461.

[29] Dong, W., Sinha, N., 2011. Where do informed traders trade? Trading around news on Dow 30 options. Working Paper, University of Illinois.

[30] Easley, D., O’Hara, M., Srinivas, P., 1998. Option volume and stock prices: Evidence on where informed traders trade. Journal of Finance 53, 431-465.

[31] Glosten, L., Milgrom, P., 1985. Bid, ask and transaction prices in a specialist market with heterogeneously informed traders. Journal of Financial Economics 14, 71-100.

[32] Green, T., 2004. Economic news and the impact of trading on bond prices. Journal of Finance 59, 1201-1233. 
[33] Harris, F., McInish, T., Wood, R., 2002. Security price adjustment across exchanges: An investigation of common factor components for Dow stocks. Journal of Financial Markets 5, 277-308.

[34] Hasbrouck, J., 1995. One security, many markets: Determining the contributions to price discovery. Journal of Finance 50, 1175-1199.

[35] Heston, S.L., 1993. A Closed-Form Solution for Options with Stochastic Volatility with Applications to Bond and Currency Options. Review of Financial Studies 6, 327-343.

[36] Ioffe, I.D., Prisman, E.Z., 2013. Arbitrage violations and implied valuations: The option market. European Journal of Finance 19, 298-327.

[37] Jackwerth, J., Rubenstein, M., 1996. Recovering probability distributions from options prices. Journal of Finance 51, 1611-1631.

[38] Jiang, G., Tian, Y., 2005. Model free implied volatility and its information contents. Review of Financial Studies 18, 1305-1342.

[39] Jones, C., Kaul, G., Lipson, M., 1994. Transactions, volume, and volatility. Review of Financial Studies 7, 631-651.

[40] Kang, J., Ahn, H., Ryu, D., 2008. Informed trading in the index option market: the case of KOSPI 200 options. Journal of Futures Markets 28, 1118-1146.

[41] Kapadia, N., Pu, X., 2012. Limited arbitrage betweeen equity and credit markets. Journal of Financial Economics 105, 542-564.

[42] Kaul, G., Nimalendran, M., Zhang, D., 2002. Informed trading and option spreads. Working paper, University of Michigan.

[43] Kendall, G.M., 1938. A New Measure of Rank Correlation. Biometrika 30, 81-93.

[44] Kyle, A.S., 1985. Continuous auctions and insider trading. Econometrica 53, 1315-1335.

[45] Lee, C.M.C., Mucklow, B., Ready, M., 1993. Spreads, depths, and the impact of earnings information: An intraday analysis. Review of Financial Studies 6, 345-374.

[46] Muravyev, D., Pearson, N.D., Broussard, J.P., 2013. Is there price discovery in equity options? Journal of Financial Economics 107, 259-283.

[47] Pan, J., Poteshman, A., 2006. The information in option volume for futures stock prices. Review of Financial Studies 19, 871-908.

[48] Yan, X., Zhang, Z., 2009. Institutional investors and equity returns: Are short-term institutions better informed? Review of Financial Studies 22, 893-924. 


\section{Table 1: Volume Statistics for Weekly and Monthly Options}

The table reports volume statistics for Weeklys and Monthlys for trade days 0 - 6 ( 0 being the last trade day). Statistics are provided for calls and puts that are near-the-money (NTM: $0.97<m \leq 1.03$, where $m=K / S$ for calls and $m=S / K$ for puts). The sample period is January 2011 to May 2012.

\begin{tabular}{|c|c|c|c|c|c|}
\hline \multirow{2}{*}{ Days } & \multirow{2}{*}{ Statistics } & \multicolumn{2}{|c|}{ Weeklys } & \multicolumn{2}{|c|}{ Monthlys } \\
\hline & & Call & Put & Call & Put \\
\hline \multirow[t]{2}{*}{0} & Volume & 674695 & 700942 & 1646443 & 2418680 \\
\hline & Share of Total $(\%)$ & 16.854 & 15.612 & 19.954 & 23.677 \\
\hline \multirow[t]{2}{*}{1} & Volume & 782963 & 955869 & 1470649 & 1821822 \\
\hline & Share of Total (\%) & 19.559 & 21.290 & 17.823 & 17.835 \\
\hline \multirow[t]{2}{*}{2} & Volume & 728946 & 884198 & 1439869 & 1560603 \\
\hline & Share of Total (\%) & 18.209 & 19.693 & 17.450 & 15.277 \\
\hline \multirow[t]{2}{*}{3} & Volume & 619936 & 584146 & 898325 & 1350936 \\
\hline & Share of Total (\%) & 15.486 & 13.010 & 10.887 & 13.225 \\
\hline \multirow[t]{2}{*}{4} & Volume & 420621 & 510425 & 947827 & 1173725 \\
\hline & Share of Total $(\%)$ & 10.507 & 11.369 & 11.487 & 11.490 \\
\hline \multirow[t]{2}{*}{5} & Volume & 450599 & 459156 & 931473 & 766292 \\
\hline & Share of Total $(\%)$ & 11.256 & 10.227 & 11.289 & 7.502 \\
\hline \multirow[t]{2}{*}{6} & Volume & 325369 & 395081 & 916751 & 1123057 \\
\hline & Share of Total $(\%)$ & 8.128 & 8.799 & 11.110 & 10.994 \\
\hline Total & Volume & 4003129 & 4489817 & 8251337 & 10215115 \\
\hline
\end{tabular}




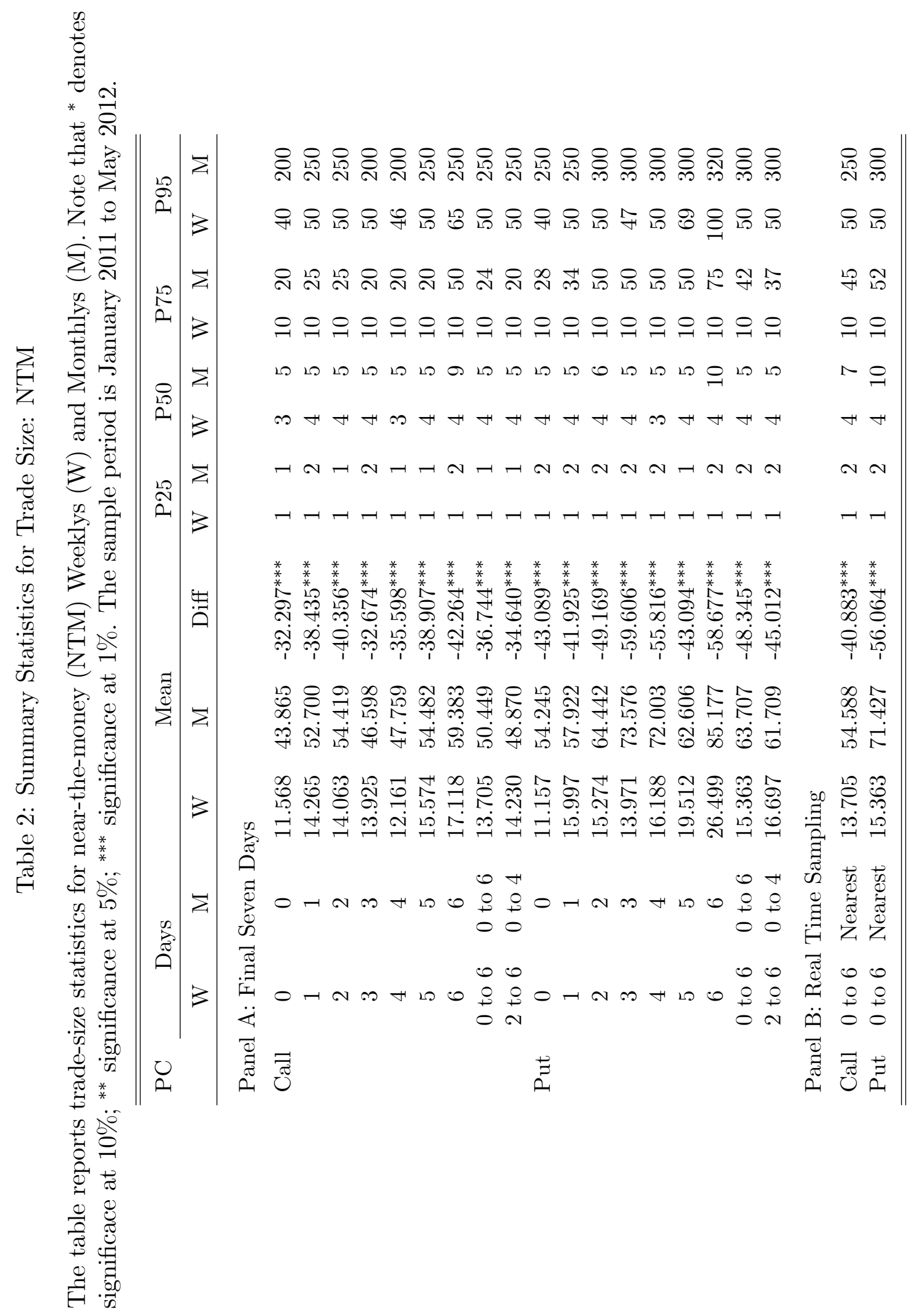




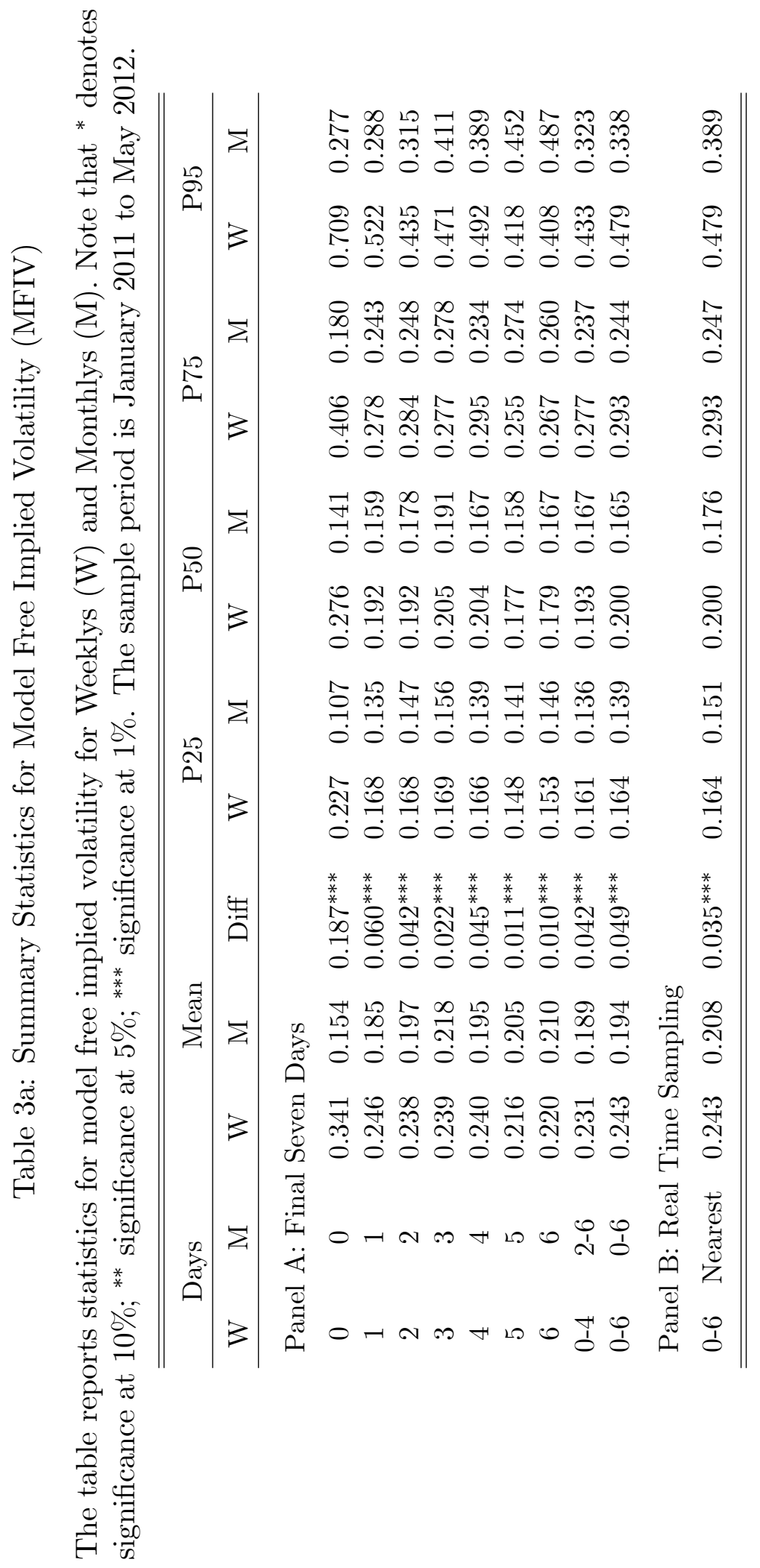




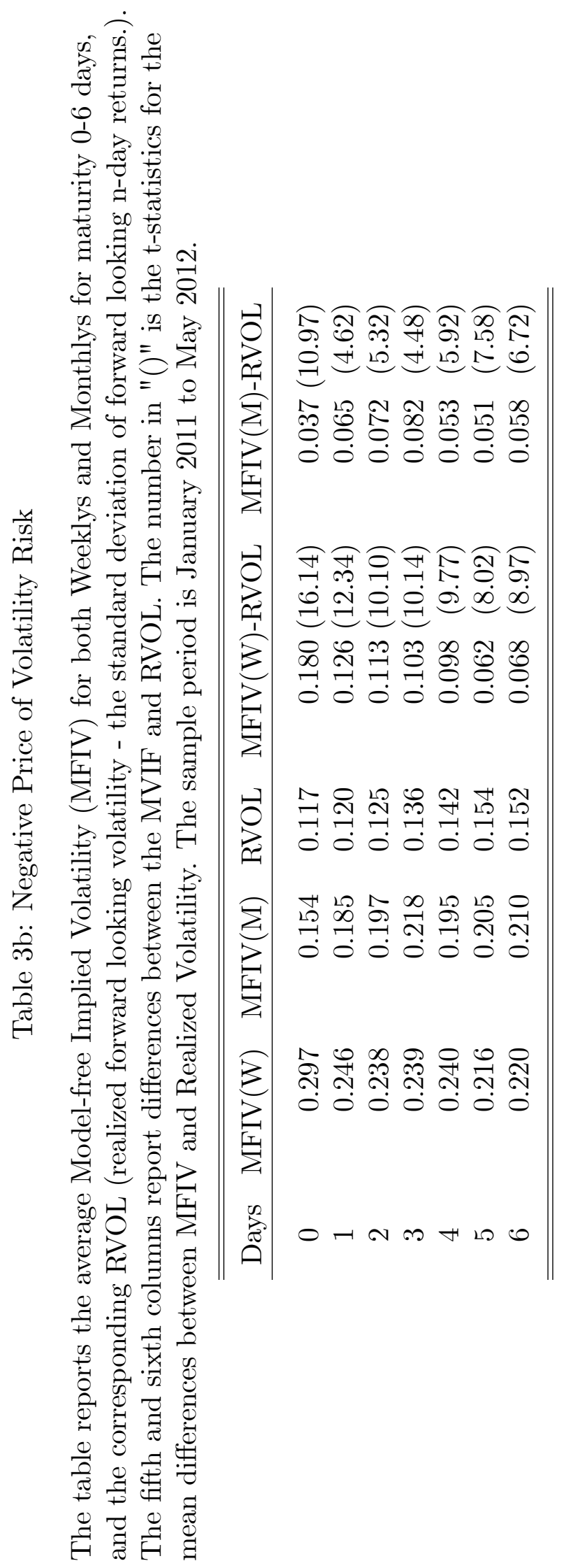


Table 4: Summary Statistics of Relative Spread and Depth: NTM

The table reports the relative spread and depth statistics for near-the-money (NTM) Weeklys (W) and Monthlys (M). Note that * denotes significance at $10 \%$; ${ }^{* *}$ significance at 5\%; *** significance at 1\%. The sample period is January 2011 to May 2012.

\begin{tabular}{|c|c|c|c|c|c|c|c|c|}
\hline \multirow[t]{2}{*}{$\mathrm{PC}$} & \multicolumn{2}{|c|}{ Days } & \multicolumn{3}{|c|}{ Relative Spread } & \multicolumn{3}{|c|}{ Depth } \\
\hline & & & $\mathrm{W}$ & M & Diff & $\mathrm{W}$ & M & Diff \\
\hline \multicolumn{9}{|c|}{ Panel A: Final Seven Days } \\
\hline \multirow[t]{9}{*}{ Call } & 0 & 0 & 0.165 & 0.221 & $-0.056^{* * *}$ & 128.19 & 152.73 & $-24.537^{* * *}$ \\
\hline & 1 & 1 & 0.100 & 0.195 & $-0.095^{* * *}$ & 172.77 & 181.95 & $-9.183^{* * *}$ \\
\hline & 2 & 2 & 0.082 & 0.189 & $-0.108^{* * *}$ & 191.84 & 185.03 & $6.815^{* * *}$ \\
\hline & 3 & 3 & 0.069 & 0.150 & $-0.081^{* * *}$ & 181.45 & 199.07 & $-17.615^{* * *}$ \\
\hline & 4 & 4 & 0.061 & 0.159 & $-0.099^{* * *}$ & 178.00 & 204.09 & $-26.086^{* * *}$ \\
\hline & 5 & 5 & 0.066 & 0.149 & $-0.084^{* * *}$ & 165.10 & 218.13 & $-53.024^{* * *}$ \\
\hline & 6 & 6 & 0.058 & 0.149 & $-0.091^{* * *}$ & 148.45 & 192.96 & $-44.511^{* * *}$ \\
\hline & 0 to 6 & 0 to 6 & 0.080 & 0.178 & $-0.098^{* * *}$ & 168.94 & 187.87 & $-18.928^{* * *}$ \\
\hline & 2 to 6 & 0 to 4 & 0.067 & 0.187 & $-0.120^{* * *}$ & 172.86 & 181.67 & $-8.813^{* * *}$ \\
\hline \multirow[t]{9}{*}{ Put } & 0 & 0 & 0.177 & 0.246 & $-0.069^{* * *}$ & 128.45 & 152.89 & $-24.439^{* * *}$ \\
\hline & 1 & 1 & 0.103 & 0.189 & $-0.086^{* * *}$ & 182.50 & 176.49 & $6.003^{* * *}$ \\
\hline & 2 & 2 & 0.075 & 0.181 & $-0.106^{* * *}$ & 195.16 & 184.69 & $10.474^{* * *}$ \\
\hline & 3 & 3 & 0.063 & 0.147 & $-0.085^{* * *}$ & 184.17 & 199.93 & $-15.757^{* * *}$ \\
\hline & 4 & 4 & 0.055 & 0.141 & $-0.086^{* * *}$ & 177.66 & 212.67 & $-35.019^{* * *}$ \\
\hline & 5 & 5 & 0.060 & 0.131 & $-0.071^{* * *}$ & 164.31 & 215.36 & $-51.051^{* * *}$ \\
\hline & 6 & 6 & 0.053 & 0.123 & $-0.070^{* * *}$ & 140.77 & 196.52 & $-55.755^{* * *}$ \\
\hline & 0 to 6 & 0 to 6 & 0.078 & 0.173 & $-0.095^{* * *}$ & 170.16 & 187.76 & $-17.605^{* * *}$ \\
\hline & 2 to 6 & 0 to 4 & 0.062 & 0.188 & $-0.126^{* * *}$ & 172.82 & 181.72 & $-8.904^{* * *}$ \\
\hline \multicolumn{9}{|c|}{ Panel B: Real Time Sampling } \\
\hline Call & 0 to 6 & Nearest & 0.080 & 0.120 & $-0.040^{* * *}$ & 168.94 & 224.05 & $-55.11^{* * *}$ \\
\hline Put & 0 to 6 & Nearest & 0.078 & 0.111 & $-0.033^{* * *}$ & 170.16 & 224.71 & $-54.55^{* * *}$ \\
\hline
\end{tabular}




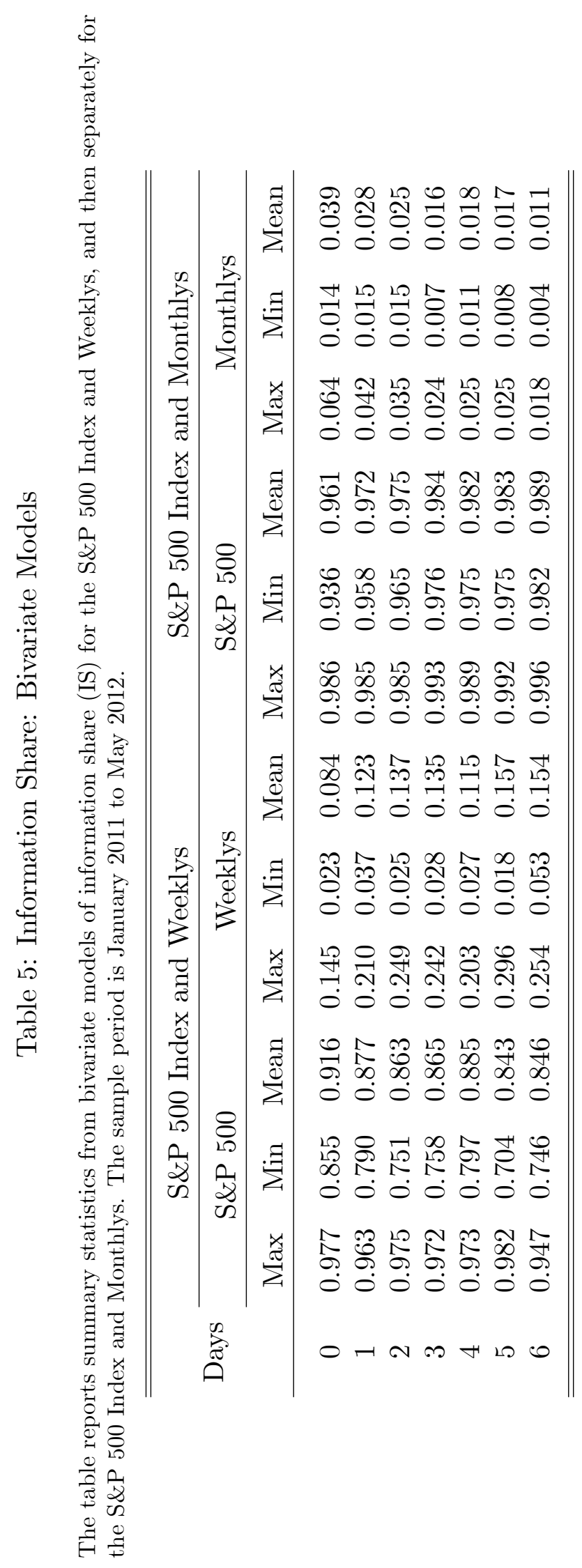


Table 6: Information Share: Weeklys and Monthlys Expirations

The table reports estimation restults from the bivariate models of information share (IS) for 0-6 days to expiration of monthlys matched with nearest-term Weeklys. The sample period is June 2012 to December 2012.

\begin{tabular}{ccccccc}
\hline \hline \multirow{2}{*}{ Days } & \multicolumn{3}{c}{ Weeklys } & \multicolumn{3}{c}{ Monthlys } \\
\cline { 2 - 7 } & Max & Min & Average & Max & Min & Average \\
\hline 0 & 0.851 & 0.769 & 0.810 & 0.231 & 0.149 & 0.190 \\
1 & 0.842 & 0.793 & 0.817 & 0.207 & 0.158 & 0.183 \\
2 & 0.877 & 0.833 & 0.855 & 0.167 & 0.123 & 0.145 \\
3 & 0.866 & 0.825 & 0.845 & 0.175 & 0.134 & 0.155 \\
4 & 0.933 & 0.901 & 0.917 & 0.099 & 0.067 & 0.083 \\
5 & 0.959 & 0.929 & 0.944 & 0.071 & 0.041 & 0.056 \\
6 & 0.948 & 0.920 & 0.934 & 0.080 & 0.052 & 0.066 \\
\hline \hline
\end{tabular}


Table 7: Abnormal Volume and Implied Volatility Around "Save-the-Euro" Meetings, January 2011 - May 2012

The table reports volume and implied volatility figures for Weeklys and the nearest-term Monthlys around twenty "Save-the-Euro" meetings between January 2011 and May 2012 (see Appendix B). These meetings take place between Euro Zone leaders, European Union Leaders, Prime Ministers, Finance Ministers, and Central Bankers. For a given trading day $t$, the abnormal volume is given by $V_{t}^{A}=\left(V_{t}^{j}-\bar{V}_{j}\right) / \bar{V}_{j}$, where $j=6, \ldots, 0$ days to maturity for Weeklys and $j=34, \ldots, 0$ days to maturity for Monthlys. Daily values for $V_{t}^{j}$ and $\bar{V}^{j}$ are obtained using the average of the intraday volume. Abnormal implied volatility is similarly constructed as: $I V_{t}^{A}=\left(I V_{t}^{j}-\overline{I V}_{j}\right) / \overline{I V}_{j}$. The Euro Zone and EU meetings are frequently held over 2 consecutive days. Therefore, the first event date of " 0 " represents the day prior to a one-day meeting, or the first day of a two-day meeting.

\begin{tabular}{|c|c|c|c|c|}
\hline & \multicolumn{2}{|c|}{$V_{t}^{A}(\%)$} & \multicolumn{2}{|c|}{$I V_{t}^{A}(\%)$} \\
\hline Day & Weeklys & Monthlys & Weeklys & Monthlys \\
\hline \multicolumn{5}{|c|}{ Panel A. Call Stats } \\
\hline-4 & 0.055 & 0.148 & 0.238 & 0.190 \\
\hline-3 & 0.437 & 0.213 & 0.209 & 0.202 \\
\hline-2 & 0.243 & 0.140 & 0.518 & 0.250 \\
\hline 0 & 0.211 & 0.137 & 0.199 & 0.210 \\
\hline 0 & 0.287 & 0.521 & 0.223 & 0.312 \\
\hline 1 & -0.054 & 0.222 & 0.257 & 0.154 \\
\hline 2 & 0.188 & 0.202 & 0.174 & 0.174 \\
\hline \multicolumn{5}{|c|}{ Panel B. Put Stats } \\
\hline-4 & 0.286 & 0.199 & 0.188 & 0.168 \\
\hline-3 & 0.708 & 0.452 & 0.222 & 0.176 \\
\hline-2 & 0.153 & 0.068 & 0.118 & 0.125 \\
\hline 0 & -0.021 & 0.187 & 0.179 & 0.165 \\
\hline 0 & 0.252 & 0.339 & 0.182 & 0.244 \\
\hline 1 & 0.027 & 0.202 & 0.177 & 0.143 \\
\hline 2 & 0.072 & -0.032 & 0.113 & 0.151 \\
\hline
\end{tabular}


Figure 1: Daily Volume (in thousands)

The figure shows daily volumes (both calls and puts) for Weeklys and Monthlys. The sample period is January 2011 to December 2012.
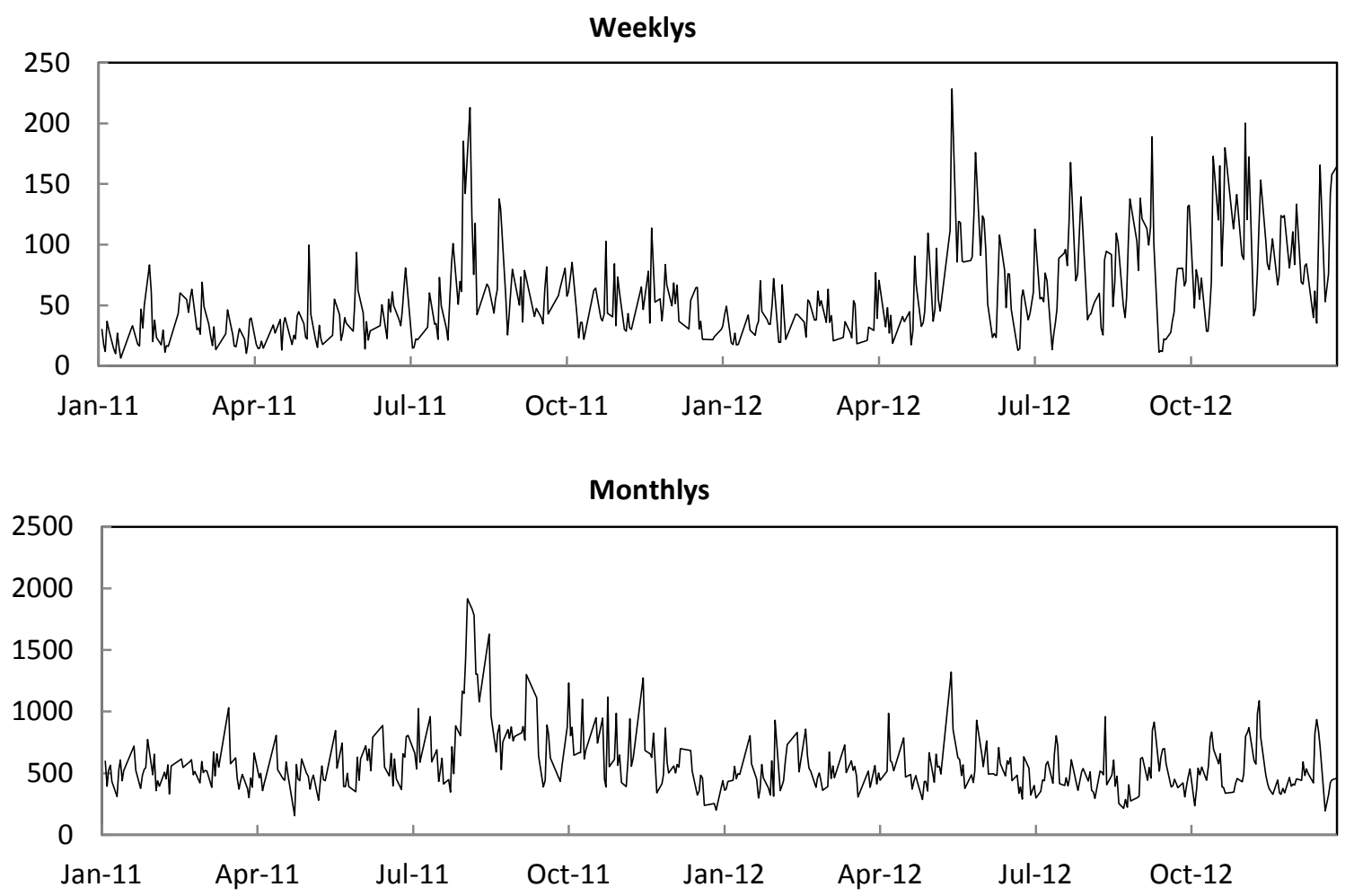
Figure 2: Daily Trades (in thousands)

The figure shows the daily number of trades for Weeklys and Monthlys. The sample period is January 2011 to December 2012.
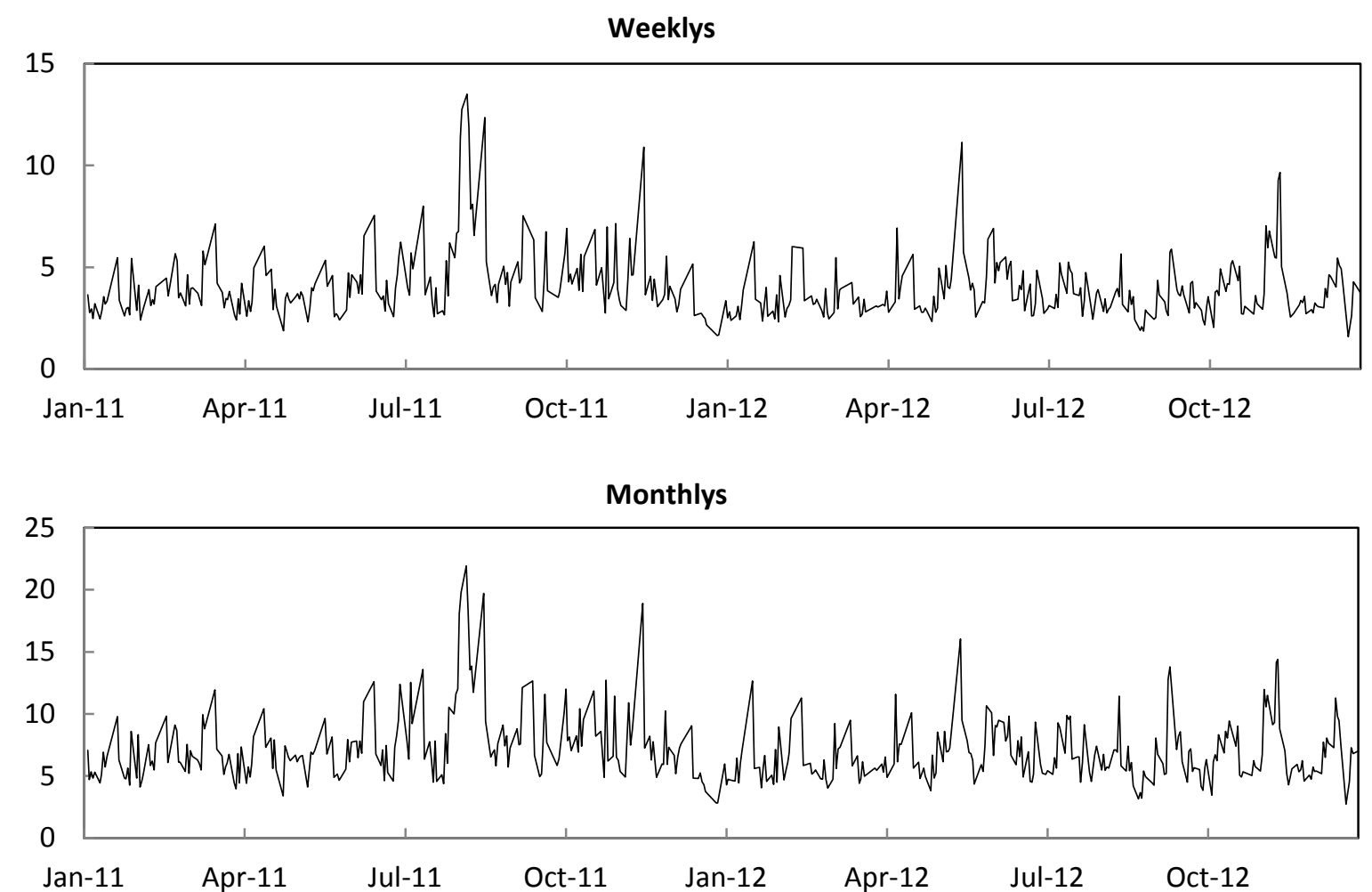
Figure 3: Daily Volume and Trades: Weeklys as a Percentage of Monthlys

The figure shows daily volume and number of trades for Weeklys (both calls and puts) as percentages of the corresponding daily volume and number of trades of Monthlys (both calls and puts). The sample period is January 2011 to December 2012.

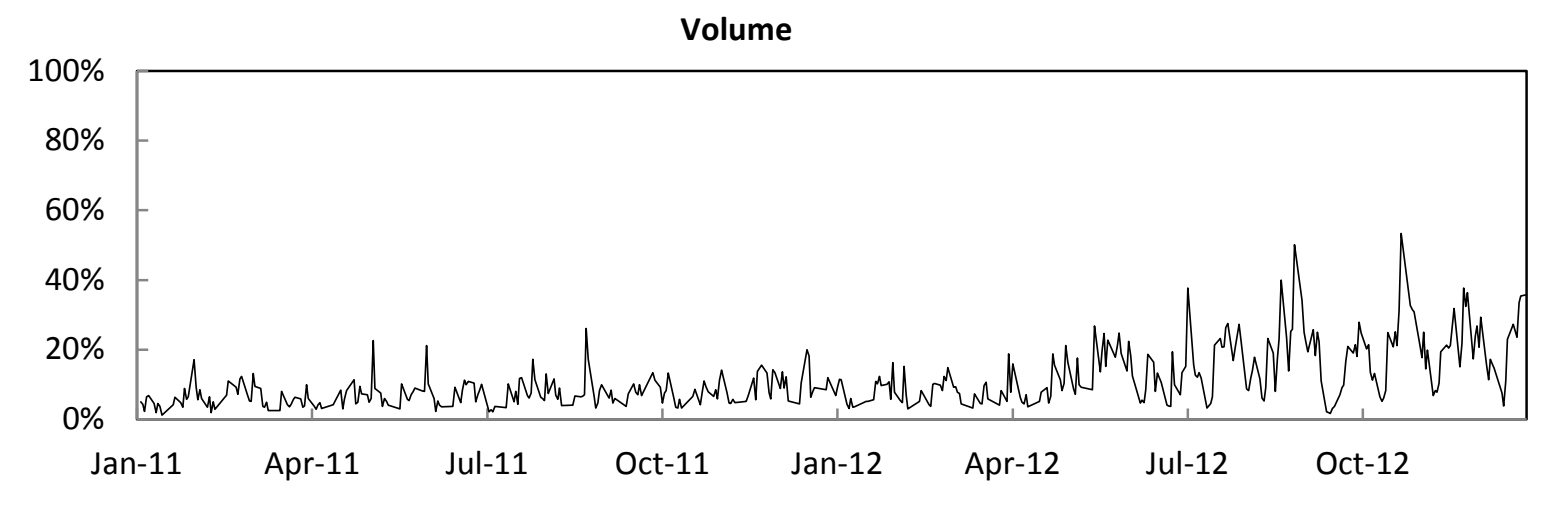

Trades

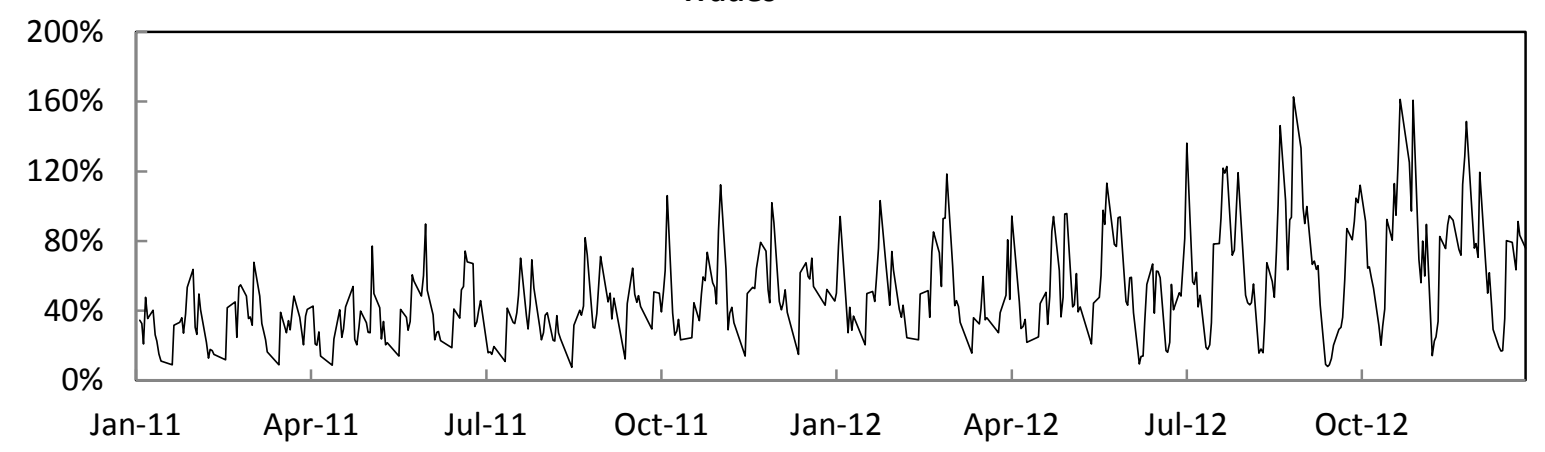


Figure 4: Model-Free Implied Volatility (MFIV) Daily Average

The figure shows daily average MFIV for Weeklys (4 day expirations) and Monthlys (30 day expirations). The sample period is January 2011 to May 2012.

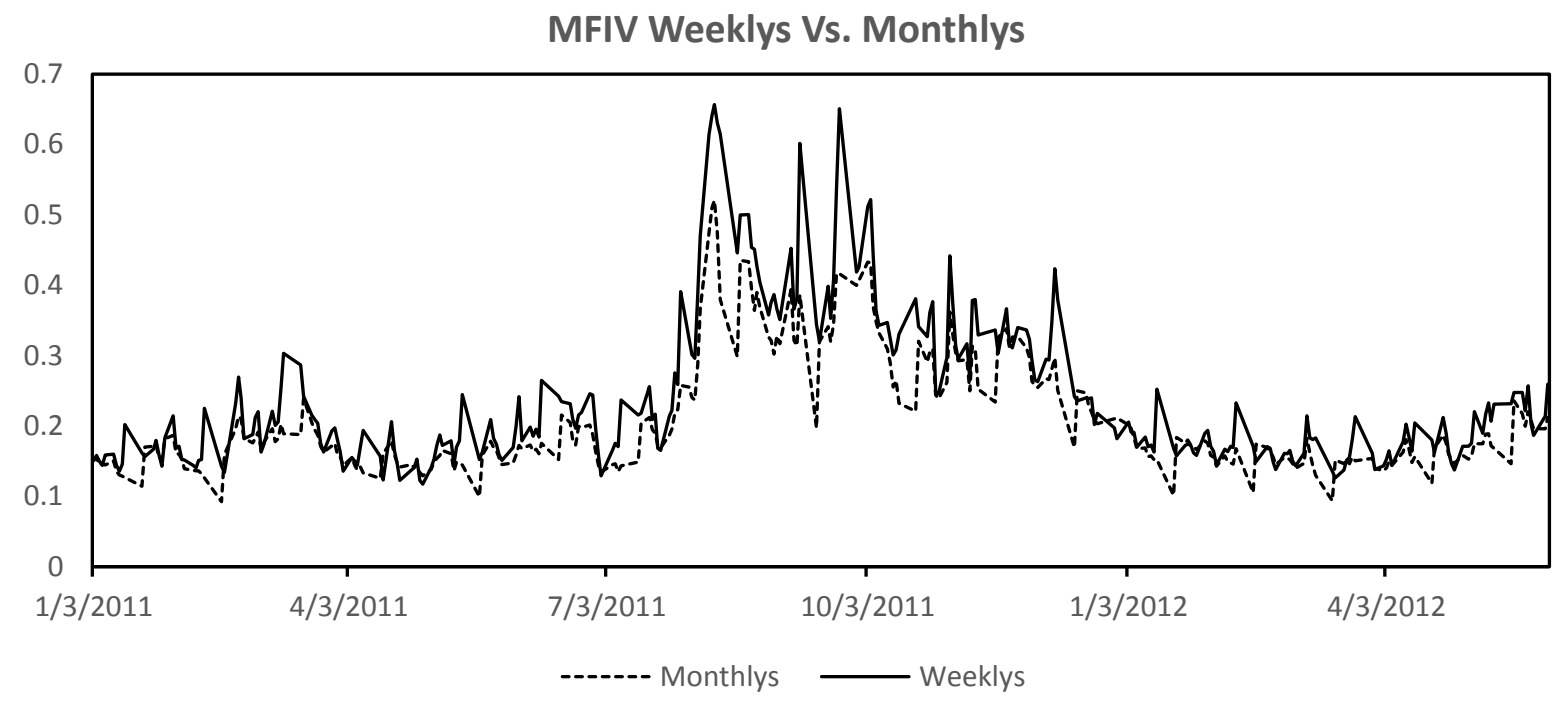


Figure 5: Call Option Boundary Violations

The figure shows upper and lower boundaries for Call Options. Following Constantinides et. al. (2009), we identify a stochastic violation when the bid (ask) price implied volatility is higher (lower) than the upper (lower) bound. We only detect upper boundary violations for Weeklys in our sample.

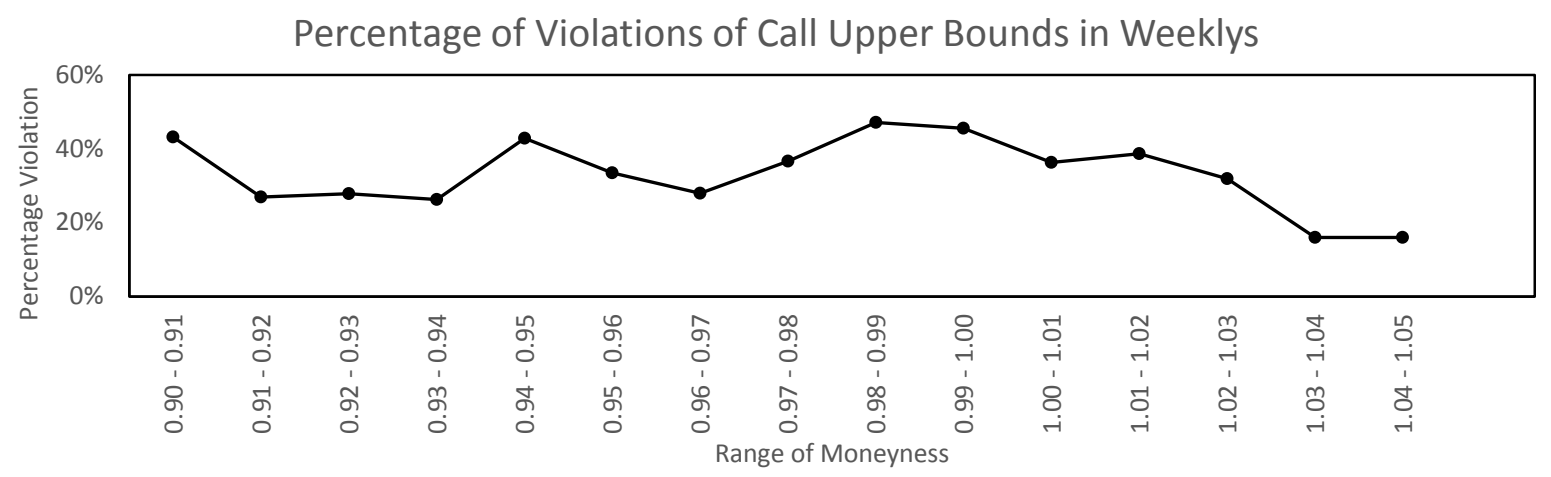

Stochastic Dominance Boundaries 4-Day Expiration Weeklys

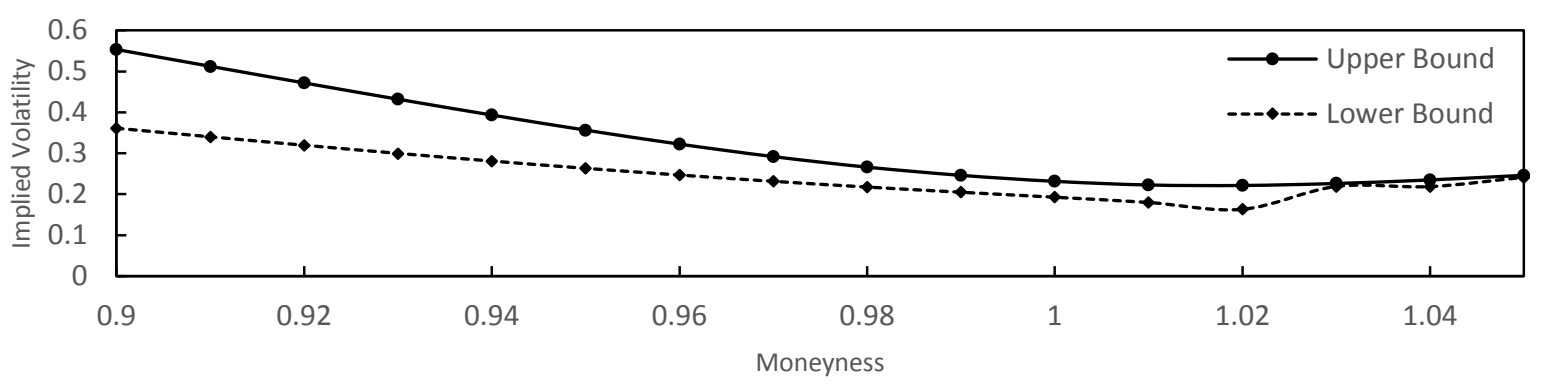

Stochastic Dominance Boundaries 30-Day Expiration Monthlys

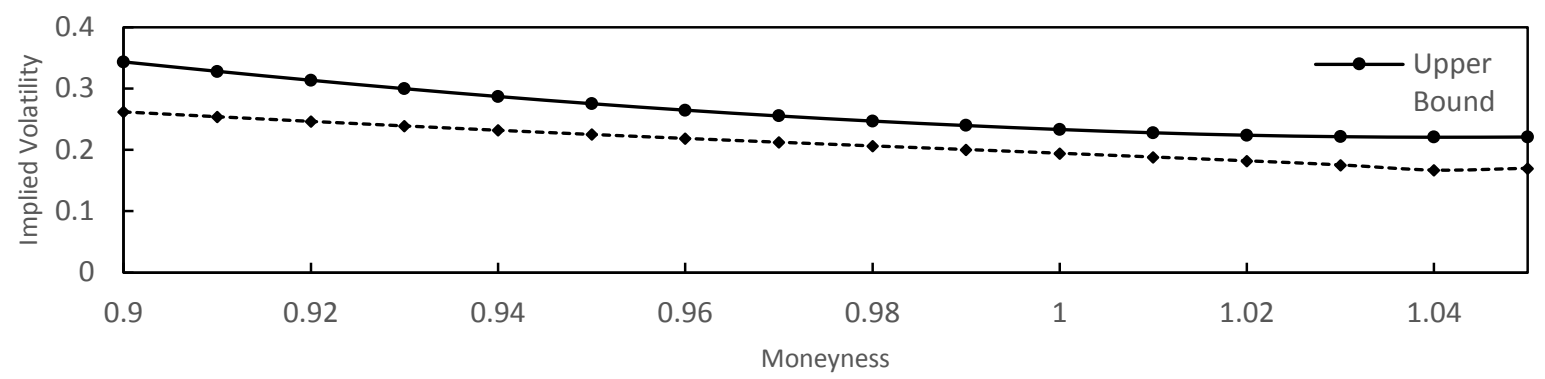


Figure 6: Time Series of Integration Index between Weeklys and Monthlys

The figure shows the time series of the intergration index. between Weeklys and Monthlys. The index value is bounded by -1 and 1 . In the absence of mispricing the index will take a value $=-1$. The sample period is January 2011 to May 2012 .

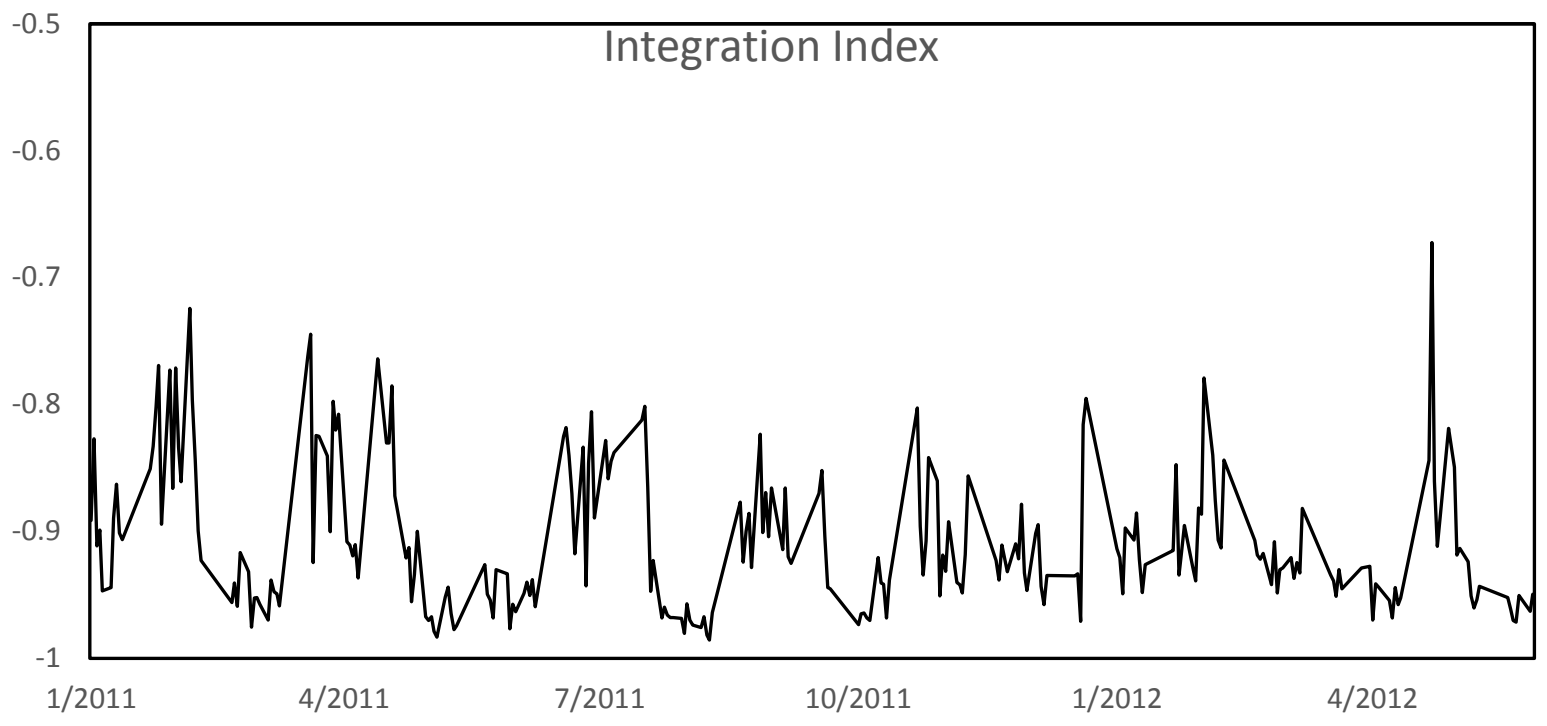




\section{Appendix A. Risk-Neutral Implied Volatility (MFIV)}

The MFIV was formalized by Britten-Jones and Neuberger (2000) under the assumptions that the underlying asset does not pay a dividend, the risk-free rate is zero, and returns follow

a diffusion process. They define the model-free implied variance as:

$$
E_{0}^{F}\left[\int_{0}^{T}\left(\frac{d F_{t}}{F_{t}}\right)^{2}\right]=2 \int_{0}^{\infty} \frac{C^{F}(T, K)-\max \left(0, F_{0}-K\right)}{K^{2}} d K,
$$

where $E^{F}$ refers to expectation under the forward probability measure, $C^{F}(T, K)$ is the forward price of a call option with maturity $T$ and strike $K$, and $F_{0}$ is the forward price of the underlying asset at time $t$.

While the model-free implied volatility is theoretically appealing, in practice, it remains computationally challenging to estimate. Because the right hand of equation 1 involves an integral of option prices over an infinite range of strike prices, it is impossible to be calculated accurately. To approximate this quantity, Jiang and Tian (2005) present an approximation. Suppose the interval of available strike prices is defined as $\left[K_{\min }, K_{\max }\right]$, then the right hand side of the MFIV equation can be approximated by the following integral:

$$
2 \int_{K_{\min }}^{K_{\max }} \frac{C^{F}(T, K)-\max \left(0, F_{0}-K\right)}{K^{2}} d K .
$$

Jiang and Tian (2005) discuss a relatively tight theoretical model-dependent upper bounds and a less tight model-free upper bounds for truncation errors when a finite range of strikes is used. In practice, a greater computational challenge of the model-free implied volatility is that we do not observe a range of continuous strike prices of calls. Therefore, Jiang and Tian (2005) suggest to further approximate the integral using the trapezoidal rule. In other words, since it is not possible to obtain a continuous series of strike prices and the range of strike prices are limited, approximation and numerical integration techniques are needed. That is:

$$
2 \int_{K_{\min }}^{K_{\max }} \frac{C^{F}(T, K)-\max \left(0, F_{0}-K\right)}{K^{2}} d K \approx \sum_{i=1}^{m}\left[g\left(T, K_{i}\right)+g\left(T, K_{i-1}\right)\right] \Delta K,
$$

where $\Delta K=\left(K_{\max }-K_{\min }\right) / m, K_{i}=K_{\min }+i \Delta K$ for $0 \leq i \leq m$, and $g\left(T, K_{i}\right)=\left[C^{F}\left(T, K_{i}\right)-\max \left(0, F_{0}-K_{i}\right)\right] / K_{i}^{2}$. 


\section{Appendix B. Euro Zone Meetings Examined}

The following Euro Zone meetings are examined. All events are from Reuters. The original titles/descriptions have been shortened.

1. February 4, 2011 - Summit of EU heads of state. Germany, France try to win backing for pact to strengthen the Euro Zone, but many in EU angered over 'fait accompli'.

2. March 4, 2011 - Fourteen EU leaders, hosted by Finland, meet to prepare a comprehensive response to the Euro Zone debt crisis. Ireland wanted easier terms, but "no free lunches."

3. March 24/25, 2011 - Full summit of EU heads of state and government. EU leaders confirmed that the EFSF, would have a higher effective lending capacity by June.

4. June 23/24, 2011 - Summit of EU heads of state and government in Brussels. Endorsed the treaty setting up the European Stability Mechanism.

5. July 21, 2011 - Meeting of Euro Zone heads of state and government in Brussels. Agree on giving the rescue fund broader powers to prevent contagion.

6. September 6, 2011 - Finance Ministers of Netherlands, Finland and Germany meet in Berlin. Row over a bilateral deal between Finland and Greece granting on collateral.

7. October 3, 2011 - Meeting of Euro Zone Finance Ministers, Central Bankers and EU Commissioners, in Luxembourg. Finance ministers agree to safeguard banks.

8. October 26/27, 2011 - Euro Zone leaders strike a deal with private banks, insurers to accept a 50 percent loss on Greek government bonds.

9. December 8/9, 2011 - Crisis summit of EU heads of state and government, Brussels. Sarkozy, Merkel lay out plan to impose penalties on states exceeding deficit targets.

10. Jan. 30, 2012 - Summit of EU heads of state and government in Brussels. Discussion on "fiscal compact" on tighter budgetary controls and permanent bailout fund.

11. February 21, 2012 - Euro Zone finance ministers meeting. Deal to provide 130 billion euros of new financing to Greece in return for cuts and reforms.

12. March 1/2, 2012 - Summit of EU heads of state and government in Brussels.

13. May 23, 2012 - Summit of EU heads of state and government in Brussels. 